NBER WORKING PAPER SERIES

THE DEFINITION AND IMPACT OF COLLEGE QUALITY

by

Lewis C. Solmon

Working Paper No. 7

CENTER FOR ECONOMIC ANALYSIS OF HUMAN BEHAVIOR AND SOCIAL INSTITUTIONS National Bureau of Economtc Research. Inc. 261 Madison Avenue, New York, N.Y. 10016

August, 1973

Preliminary; Not for Quotation

NBER working papers are distributed informally and in 1imited number for comments only. They should not be quoted without written permission.

This report has not undergone the review accorded official NBER nublications; In particular, it has not yet been submitted for approval by the Board of Directors.

This project was performed pursuant to a grant to NBER from the U.S. Office of Education, Department of H.E.W. The opinions expressed herein, however, do not necessarily reflect the position or policy of the U.S. Office of Education, and no official endorsement by the U.S. office of Education should be inferred. 
II. Formulation of a Testable Model

III. The Empirical Estimates

IV. The Interaction Between Years of Schooling and college quality

V. Results at Different Points on the Life Cycle

vI. How Quality Makes Its Impact

vII. The Trade-off Between quantity and Quality of Education

VIII. The Differences in Effects of quality in Public and in Private Institutions

IX. The Interaction Between School quality and the Ability of the Individuals who Attend

x. The Introduction of Family Background Variables

XI. Implications 
LIST OF TABIES

1 Correlations Between the Various Measures of College Quality

Regression Relationships Among quality Variables

3 A Comparison of Earnings Functions for Graduate Students Using Roose-Anderson and Courman Quality Measures

4 Tests of Serial Correlations of Average Faculty Salary

5 Rankings of Graduate Institutions over Time

6 Earnings Functions with Different Aspects of College Quality

7 Earnings Functions with Several Quality Variables

8 Earnings Functions Including Both Undergraduate or Graduate quality As Separate Variables

9 Separate Earnings Functions for Those With Undergraduate Training Only and for Those With Graduate Work

10 Earnings Functions for Hore Pinely Separated Levels of Schooling Attainment

11 Earnings Functions at Different Times in the Iife Cycle Using Various Measures of Quality and Pooling the sample

12 Earnings Functions at Different rimes in the Life Cycle Using Gourman Ratings and Dividing the Sample into Those with only Undergraduate Training and Those With Some Graduate Work

13 Earnings Functions at Different Times in the Life Cycle Using Expenditures on Faculty, Research, and Library and Dividing the Sample Into Those With Only Undergraduate Training and Those With Some Graduate Work 
LIST OF TABLES (concluded)

14 Regressions to Explain Rate of Change of Income Between 1955 and 1969

Earnings Functions for Undergraduates by Institutional Quality Quartiles

Earnings Functions for Graduates by Institutional Quality Quartiles

Earnings Functions with Quality Quartiles in Single Regressions by Attainment

Earnings Functions with Quality Eighths in Single Regressions by Attainment

19 Earnings Functions for Groups of Individuals Sorted Into Carnegie Type of Institutions

Earnings Functions for Those with Graduate Training Sorted According to Quality Quartile of Undergraduate Institutions

21 Earnings Functions for Undergraduates Sorted According to Whether They Attended Public or Private Institutions

22 Earnings Functions for Those with Graduate Training Sorted According to whether They Attended Public or Private Institutions

Income Elasticities of Quality by IQ Above or Below the Mean

Regressions for Undergraduates and Graduates by IQ Quartiles

25 Regressions with Quality Interacting With IQ Quartiles in Single Regressions by Attainment

26 Earnings Functions for Individuals Sorted According to High or Low Individual Ability and to High or Low Institutional quality

27 Earnings Functions Including Socioeconomic Background variables 


\section{THE DEFINITION AND IMPACT OF COLLEGE QUALITY}

Lewis C. Solmon

Board on Human Resources, National Research Council, Washington, D.C. and

National Bureau of Economic Research, New York, N.Y.

\section{Introduction}

Many people have opinions on which colleges are of good quality and which are poor, the bases of these judgments can range from the number of Nobel Laureates on the faculty to the national ranking of the football team. A more systematic analysis of quality would try to identify the features of colleges which enable those whom the colleges are serving (students, alumni, taxpayers or society as a whole) to best achieve their goals. Here we are concerned with the characteristics of colleges which serve to increase subsequent monetary incomes of those who attend.

Usually, lifetime earnings are explained by variables such as innate ability, experience in the labor force, and years of education, although other socio-economic, demographic and occupational data can be inserted to increase the explanatory power of the model. This paper attempts to add a new dimension to the earnings function analysis by hypothesizing the features of colleges which might yield financial payoffs in later life, and then testing to see which of these traits actually do add most to the explanatory power of the txaditional earnings function. Several methods of identifying the mechanism by wich these quality traits affect income will be tested, including rates of return to quality estimates and tests 
for the interaction of school quality with individual ability and with years of schooling, and also interactions among the various quality traits.

There is a particular timeliness to this study. Several years ago in his classic study, James Coleman argued that for elementary school students differences in the characteristics of the schools that they attended were unimportant compared to differences in other variables, in particular, family background, in determining differential achievement rates among students. ${ }^{1}$ More recently, Christopher Jencks has minimized the effects of schooling in reducing cognitive and economic inequality. ${ }^{2}$ samuel Bowles, 3 an economist, and Alexander Astin, 4 a psychologist, have come to similar conclusions that differences in schools at various levels ranging from elementary to higher education have only small effects on student changes be they economic or cognitive. However, Astin ${ }^{5}$ does find that college

${ }^{1}$ Coleman, J.S., Campbell, E.Q., Hobson, C.J., McPartland, J., Mood, A.M., Weinfeld, F.D., and York, R.L. Equality of Educational Opportunity. Washington, D.C.: U.S. Department of Health, Education, and Welfare, U.S. Government Printing office, 1966.

2

${ }^{2}$ Jencks, C., et al. Inequality, A Reassessment of the Effect of Family and Schooling in America. New York: Basic Books, 1972.

3 Bowles, S. "Schooling and Inequality from Generation to Generation," Journal of Political Economy, 1972,80 (3, Pt. 2): S219-S251.

4 Astin, A.W., "Undergraduate Achievement and Institutional 'Excellence'", Science 1968, 161 (August): 661-668.

${ }^{5}$ Astin, ibid. 
students demonstrate differential changes in affective behavior depending upon the quality of the colleges they attended. Moreover, Spaeth and Greeley found that their measures of quality had effects on occupational prestige even after the addition of a number of other variables, which seemed to have reduced quality to insignificance in the studies previously referred to. 6

Eric Hanushek found for a sample of elementary schools that even though differences in expenditures did not seem to affect the learning rates of children, there were certain measurable characteristics of teachers which did have an impact. In particular, Hanushek found that differences in teachers' verbal aptitudes, the newness of their training, and racial differences, which he interprets as differences in quality of the training of teachers, did significantly influence children's facility in learning. ${ }^{7}$ An implication of this result is that expenditures don't matter because school monies are spent on the wrong things. If school expenditures are for seniority primarily rather than for verbal aptitudes, quality of training, and recentness of training, then we would expect little relationship between expenditures and other quantifiable measures of quality to the effectiveness of the school.

${ }^{6}$ Spaeth, J.L., and Greeley, A.M. Recent Alumni and Higher Education, A Survey of College Graduates. Report prepared for the Carnegie commission on Higher Education. New York: McGraw-Hill, 1970.

${ }^{7}$ Hanushek, E.A. Education and Race, An Analysis of the Educational Production Process. Lexington, Mass.: D.C. Heath and Company, 1972. 
To jump ahead to the major conclusion of this study, we find that at the college level, differences in quality have highly significant effects on differences in lifetime earnings patterns of students. These results hold even after controlling for a wide array of other factors, including individual student ability. It might be that expenditures at the college level are more likely to purchase those inputs that will be effective. During the period of our study, institutions of higher education were less restricted by unions, teacher associations, and school boards in regard to the types of inputs that they were able to purchase. Hence, even if the same model were applicable to all levels of education, the input-output relationships predictably should have been more effective at the college level. It is a moot point whether the superior effectiveness of higher education will be able to continue as unionism and other restrictions grow at the college level.

Our enthusiasm for the relevance to policy of the current study must be tempered somewhat because of the nature of the sample. It is usually the case in social science research on micro data sets that certain desirable characteristics of a sample to be studied will have to be sacrificed in order to get other desirable characteristics. Some samples that have attempted to follow groups of individuals over a number of years have found drop-off rates in responses that result in terrible biases. Other groups studied have had high response rates at the expense of reducing the representativeness by selecting individuals from a particular state or group of high schools, for example. Other data sets 
have of necessity lacked a number of particularly crucial variables, as is the case when survey research is unable to acquire aptitude test scores of the individuals being studied. Our sample has been characterized by statistically acceptable response rates and also by the availability of virtually all of the vital variables required for the models to be specified below. However, the representativeness of the sample has had to suffer.

The data used is now known as the NBER-Thorndike sample, and although it has been described in detail in several other places, ${ }^{8}$ we might summarize its important characteristics here. The respondents were white World War II veterans, all of whom took a battery of aptitude tests in 1942 to determine if they were qualified to be pilots. To take the test one had to have above-average $I_{Q}{ }^{9}$ and be in good health. Those willing were surveyed by Robert Thorndike in 1955 and by the National Bureau of Economic Research again in 1969. They provided much information on earnings history, socioeconomic situation, and educational experience, including the names of colleges attended as well as aptitude test scores. ${ }^{10}$

For example, Taubman, P., and Wales, T. Education as an Investment and Screening Device. New York: National Bureau of Economic Research, forthcoming.

9 The IQ variable used is a combination constructed by factor analysis of several of the AFQT tests and has a mean of . 30 and a standard deviation of 1.86 .

${ }^{10}$ Ten thougand of these World War II veterans were surveyed by Thorndike, and his work resulted in a book, Ten Thousand Careers. The same 10,000 people were sought by the National Bureau of Economic Research in 1969, and approximately 6,000 of these people provided usable information to us. 
This particular sample precludes us from generalizing some of our results so that they might be most relevant for current policy debates. In the first place, no blacks are included in the sample, and also there are no people from the lower half of the IQ distribution. Hence, we must continually keep in mind that our results apply primarily to white, high-ability members of our population. We must constantly be cautious of the temptation to apply our results to blacks, other minorities, women (who are also not represented in our sample), and the less able members of our society. If one argues that the models developed in the work reported here apply directly to these groups, then inferences about them might be made. However, if we feel that the factors determining the earnings functions for these groups are different from those determining the earnings functions for the ones in our sample, or if we feel the relationships between the factors and earnings would differ between these groups, then we will have to restrict our conclusions to the group studied. Rather than waiting for the perfect data set, we shall present the results for the data that we have developed. The caveats just stated must be kept in mind. However, the basic result--the significance of quality of college attended on lifetime earnings patterns--is important enough to justify what follows.

Two general types of attributes of colleges can be isolated and measured (if imperfectly). They are as follows:

1. Student quality. The argument is that a student benefits more from college, and hence acquires more of whatever colleges give that enhances future earning power, when surrounded by high quality fellow 
students. This has been called the peer effect. Intuitively, it does seem that the opportunity to interact with intelligent and motivated peers should enrich the college experience. We have several measures of average student quality by schools: the average Scholastic Aptitude Test (S.A.T.) scores of entering freshmen, ${ }^{11}$ and an index of intellectuality of students obtained by Alexander Astin through factor analysis. ${ }^{12}$ Another variable which has been developed by Astin, an index of selectivity based upon average level of S.A.T. scores is also used as a dimension of quality.

2. Instructional quality. The second aspect of college quality is the excellence of faculty. The hypothesis here is that better faculty instill in students traits which will be beneficial in subsequent years. One measure of faculty quality is average faculty salary. ${ }^{13}$ The assumption is that higher paid faculty have either more experience (and higher rank), better teaching ability, more professional prestige from research, or greater opportunities to earn elsewhere; all of these being indicators

${ }^{11}$ of course an individual's IQ will be highly correlated with his S.A.T. scores. However, here we are looking at the effect of average S.A.T.'s of all students at a college on an individual's subsequent income, controling for the individual's IQ.

$12 \mathrm{~J}$. Cass and M. Birnbaum, Comparative Guide of American Colleges, Harper and Row, 1969 gives S.A.T. scores; A. Astin, who Goes Where to College? Science Research Associates, 1965 gives the intellectuality and selectivity indices.

13 AAUP, "The Economic Status of the Profession," AAUP Bulletin, Summer, 1964. Data are for 1963-64. 
of greater productivity in their professorial roles. 14 Another measure of school quality is school expenditure for instruction, research and library per full-time equivalent student. Here, the argument is that high quality faculty are attracted by expenditures beyond those on salaries alone. Also, holding these expenditures per faculty member constant, a larger expenditure per student implies a greater teacher/student ratio. ${ }^{15}$ Thus, this measure is a test of the influence of teacher/student ratios as well. The hypothesis is that both expenditures per faculty member and faculty per student are aspects of quality. ${ }^{16}$ Unfortunately, data of this kind ignore differing definitions of "full-time faculty" at different colleges. Teaching loads range from one course to four or more per semester at different colleges and these differences may alter teacher effectiveness. Other problems with this proxy for quality arise since it allows for no nonpecuniary attractiveness of particular colleges for particular faculty members. Schools located in undesirable areas (urban ghettos with high crime rates or isolated rural areas with no cultural life) may be forced to pay high salaries for even mediocre quality faculty.

14 one might ask about the relationship between these traits and academic salaries; and also which of these have more important affects on "students' later incomes. However, data limitations enable us here only to look at the gross relationship between faculty salaries and student incomes.

${ }^{15}$ This is true if we assume contact hours per faculty member are constant. Obviously: $\frac{\text { Exp. }}{\text { Stu. }}=\frac{(\text { Exp })}{(\overline{\text { Fac }})} \times \frac{\text { (Fac.) }}{(\text { Contact Hrs.) }} \times \frac{\text { (Contact Hrs.) }}{\text { (Student) }}$

${ }^{16}$ Quality can be thought of as attributes of colleges which increase learning which, in turn, makes students able to earn larger incomes in later life. 
Schools with attractive surroundings (scenery, a few top scholars, cultural life or exceptionally good research and teaching equipment and plant) may be able to attract high quality faculty for low salaries. Low salaries may be paid to top quality faculty where opportunities for lucrative outside consulting jobs abound. Of course, students may or may not get benefit from "good" faculty who are away consulting much of the time. In any case, the hypothesis we will test is that schools which pay large salaries to faculty members who meet relatively small groups of students are more beneficial to students' subsequent earning power than those which pay low salaries or have large classes.

A related quality measure refers to the total incomes or expenditures per student of the colleges. It might be argued that schools which spend (or receive) larger amounts per enrollee provide a higher quality education, an educational experience more beneficial in postschool years.

As an additional test of school quality we have a subjective measure made by Gourman. These ratings propose to be a "consensus of reliable opinion and judgment obtained from many and various sources deemed to be dependable and accurate. 17 The study evaluates individual departments as well as administration, faculty, student services and other general areas such as library facilities. An average of all items is calculated,

17 Gourman, J. The Gourman Report. Phoenix: The Continuing Education Institute, 1967. 
resulting in an overall Gourman Index between 200 and 800 . The interpretation of these ratings depends upon the weights given to the various criteria. Unfortunately, these weights are not published. However, the index is one of the few quantitative ratings of a large number of colleges.

There is a question of whether or not all the measures of quality are really standing for the same thing. Table 1 presents correlations between pairs of college attributes. In general these exceed .5 .

Table 2 presents regressions with individual colleges as units of observation. These enable us to consider the relationships between the nonmonetary quality measures and the expenditure data and school size. It is obvious that the non-dollar quality measures are significantly influenced by expenditures as a whole, faculty salaries, and size of student body. Size is negatively related to average S.A.T. scores and the Astin measures; that is, better peer group influences apparently are found in smaller schools. Gourman ratings are positively influenced by size. Interestingly, we explain about 50 per cent of the variance in the peer group measures by our model, but 70 per cent of the Gourman ratings are explained.

It is interesting to compare these relationships with those discussed by Charles Elton in a recent paper. ${ }^{18}$ Elton finds that in quality ratings of graduate departments made by people engaged in academic careers, there is a very strong relationship between size of department and its quality rating.

${ }^{18}$ Elton, Charles F., and Rodgers, Sam A. "The Departmental Rating Game: Measure of Quantity and Quality?," Higher Education, Vol. 2, No. 4, 1973. 


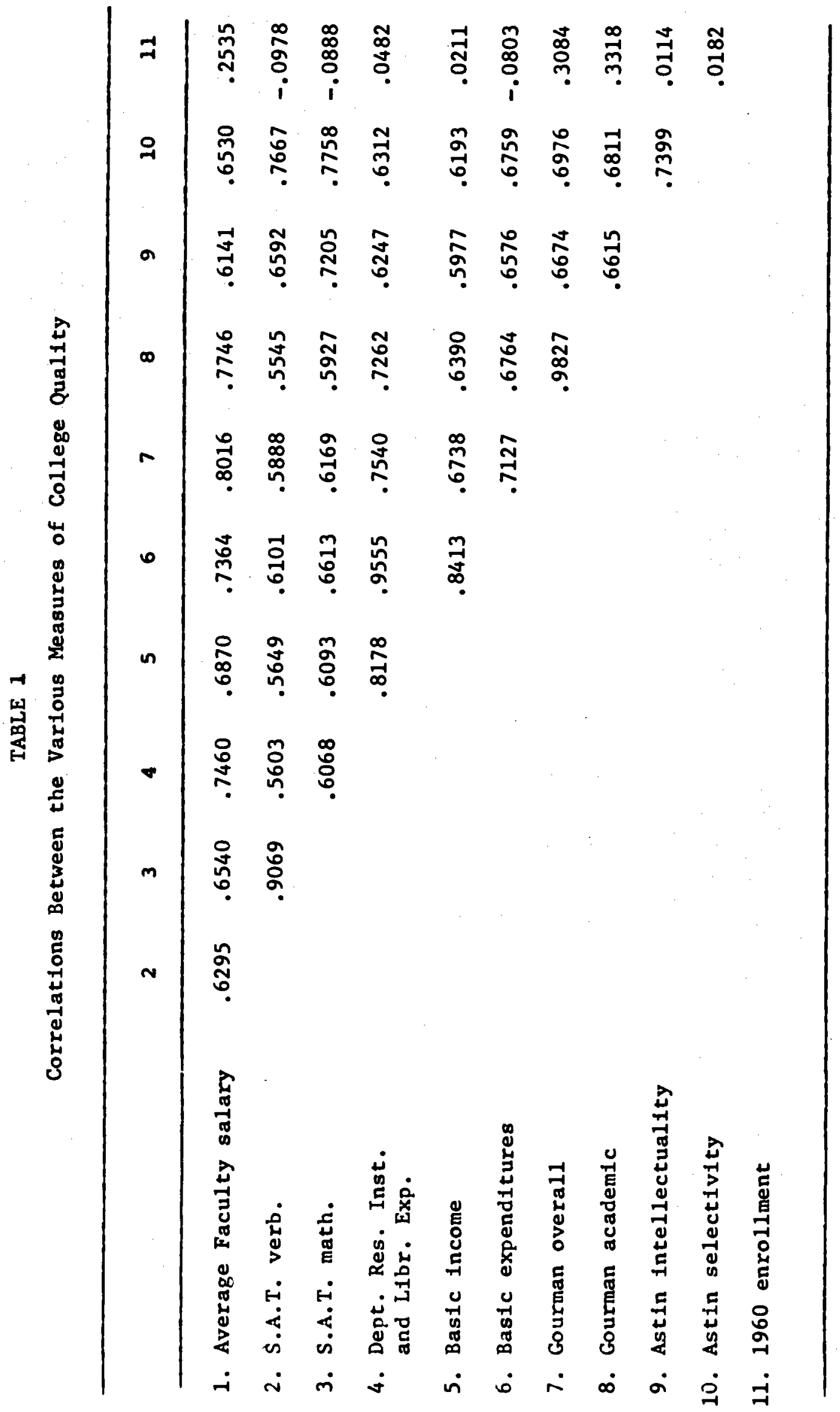




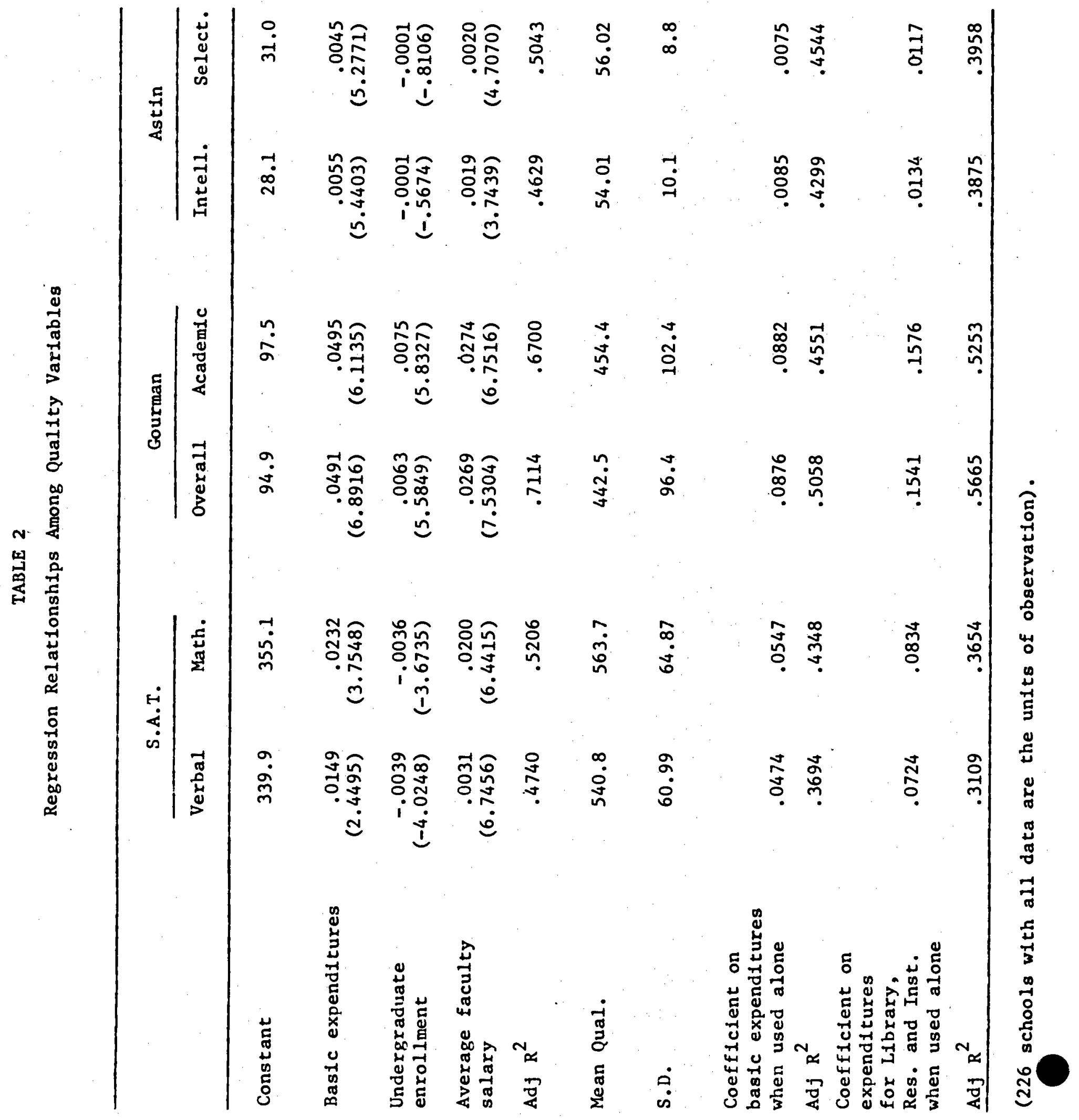


Elton correlated the quality measures obtained by Allan Cartter ${ }^{19}$ and by Roose and Anderson ${ }^{20}$ with the number of areas of specialization within a department, number of faculty, number of Ph.D. degrees awarded, number of full-time students, number of first-year students, and ratio of part-time to full-time students. He found that tests of statistical significance indicated that these variables differentiated the departmental ratings beyond chance expectations. He concludes that in the ratings obtained from opinion-poll type surveys, the prime determinant of the probability of a department having a high-quality rating is its size, as measured by the variables noted. The Gourman ratings that we use resemble the Cartter-type ratings in that they are derived from opinions of an individual. It is for this quality variable that undergraduate enrollment is significantly and positively related to the institutional rating. On the other hand, enrollment or institutional size is negatively or insignificantly related to measures of average SAT scores of entering freshmen, either those obtained from Cass and Birnbaum ${ }^{21}$ or those derived

${ }^{19}$ Cartter, A.M. An Assessment of quality in Graduate Education. Washington, D.C.: American Council on Education, 1966.

${ }^{20}$ Roose, K.D., and Anderson, C.J. A Rating of Graduate Programs. Washington, D.C.: American Council on Education, 1970.

${ }^{21}$ Cass, J., and Birnbaum, M. Comparative Guide of American Colleges. New York: Harper and Row, 1969. 
by Alexander Astin. ${ }^{22}$ The implication is that we might want to focus on quality measures, at least in part, which are based on more or less objective data rather than exclusively on quality variables derived by surveying opinions.

It should be noted that quality variables used below are based efther on undergraduate evidence, like the SAT-score data, or on university-wide characteristics, such as expenditure data and the Gourman ratings. In other words, a school is evaluated equally regardless of whether an individual attended it as a graduate or an undergraduate student. An implicit assumption in these cases is that the quality rankings of an institution in its undergraduate schools do not differ from the quallty rankings based on 1ts graduate programs.

We do have ratings of graduate schools that have been prepared by specific departments. We were less anxious to make use of these graduate ratings for a number of reasons. If we could specify not only the institution attended for graduate training by the individual in our sample but also the department, then the departmental ratings by graduate schools would be optimal. However, since we do not know what departments were attended by our respondents, we would be forced to weight the ratings of the different departments and combine them into one rating of the graduate institution as a whole. Secondly, most of the departmental ratings of graduate schools are provided for only a certain number of schools, particularly the best

\footnotetext{
22 Astin, A.W. Who Goes to College? Chicago: Science Research Associates, 1965.
} 
schools. Although the Roose-Anderson ratings have been expanded to cover well over 100 graduate schools, many of those graduate schools attended by our respondents were not included. In our sample only 775 people attended graduate schools that had Roose-Anderson ratings. One thousand and ninety-two people attended graduate schools that had our Gourman ratings.

However, we did want to make sure that using university-wide ratings (Gourman) was not a significantly inferior strategy than that of using the Roose-Anderson ratings for those who attended graduate school. Table 3 makes the appropriate comparisons. In our earnings function, which is developed below, we insert in the first column the quality of the undergraduate and graduate schools attended, as measured by Gourman, and in the second column, the quality of the undergraduate school as measured by Gourman and of the graduate school as measured by Roose and Anderson. The explanatory power of the model is virtually Identical to two decimal places. Moreover, this significance of the graduate quality variable is almost identical as well. Other variables have similar effects also. Comparing column 1 and column 4 reveals that the results using Gourman quality measures for both the undergraduate and graduate institution do not vary too much depending upon the size of the sample, the larger sample being all individuals who attended graduate schools with Gourman ratings and the smaller sample being all those who attended graduate schools with Roose-Anderson ratings.

Finally, it is evident from column 3 that the use of the RooseAnderson rating of graduate schools along with the Gourman rating of 
TABLE 3

A Comparison of Earnings Functions

For Graduate Students Using

Roose-Anderson and Gourman Quality Measures

Small Sample

Large Sample

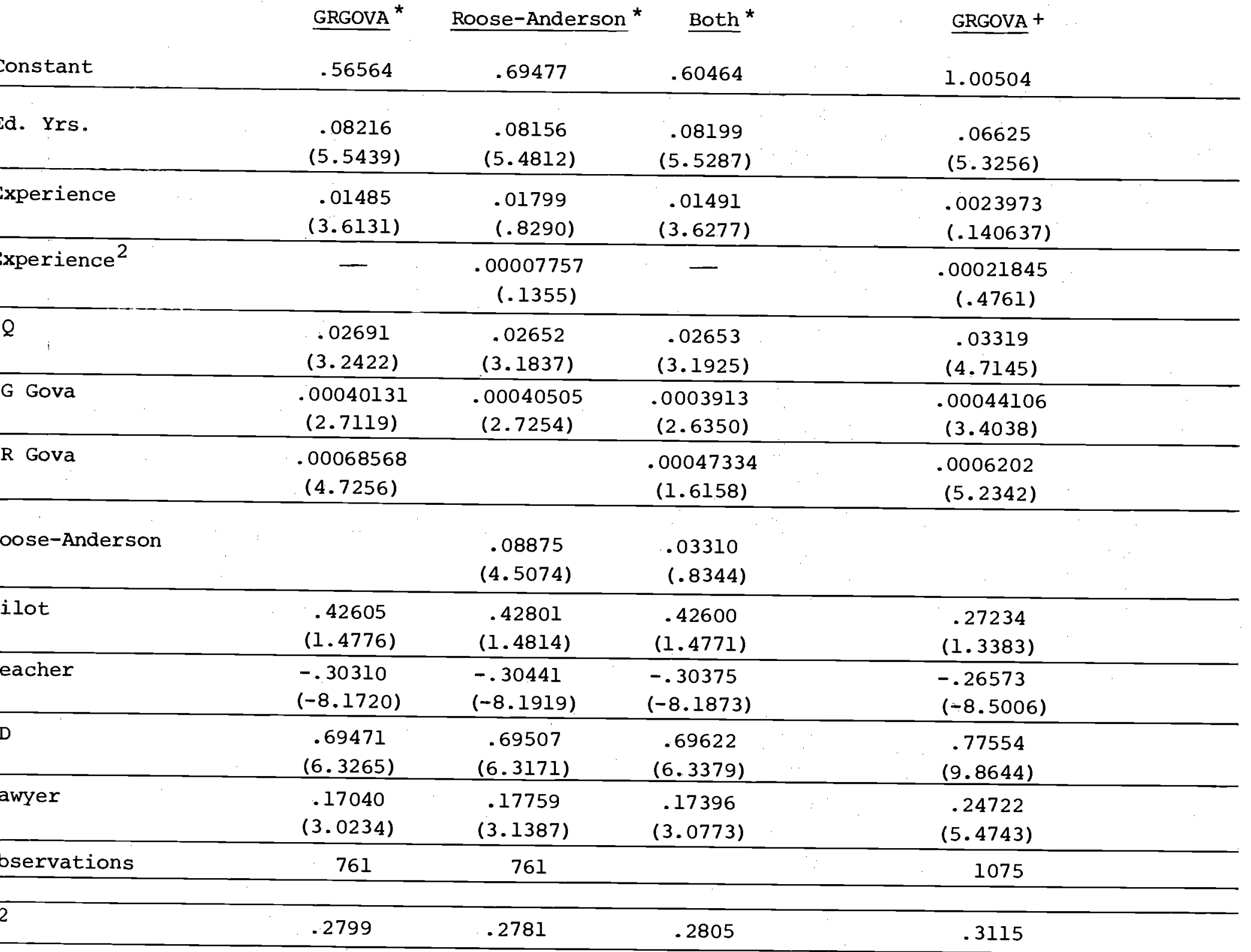

eliminate if both quality variables = blank not eliminating when $\mathrm{R} / \mathrm{A}$ absent 
graduate schools does not improve the power of the model very much. Indeed, when the two graduate-quality variables enter together, the high degree of correlation between them reduces their individual coefficients to statistical insignificance.

Given these results, it was decided that the work of this study would be conducted without using the Roose-Anderson ratings of graduate schools . So the rating of a school is the same whether an individual attended it as an undergraduate or a graduate student. If the other approach had been used, the results would not have been significantly different.

\section{Formulation of a Testable Model}

Investments in human capital serve to increase people's skills, knowledge and similar attributes which, in turn, enhance their capabilities to do productive work. One function of schools is to increment the productive capacities of those who attend--to increase their human capital. Of course, there are other ways of augmenting human capital besides formal schooling (e.g., investments in health and on-the-job-training).

A student acquires human capital in school by combining his own time and abilities with the resources provided by the institution. Formally, we can think of a production function for human capital through schooling in any period as:

$$
\Delta H_{1}=f\left(R_{1}, T_{1}, B\right)
$$

where $\Delta \mathrm{H}_{1}$ is the number of units of productive capital acquired by a person in period 1 from attending school, $R_{1}$ is the 8 chool's rate of input of 
market resources, $T_{i}$ is the rate of input of the investor's time per unit of calendar time, and $B$ is the individual's physical and mental powers. We would expect the three variables on the right side of (1) to interact with each other.

Up to period $t$, total human capital acquired from schooling would be

$$
H_{t}=\sum_{i=1}^{t} f\left(R_{i}, T_{i}, B\right)
$$

(1') is specified as a linear relationship so

$$
H_{t}=\sum_{i=1}^{t} f\left(R_{1}, T_{i}, B\right)=\alpha \Sigma R_{1}+B \Sigma T_{1}+B
$$

It is assumed that the individual's skills, $B$, do not change. We allow for interactions of $R, T$, and $B$ later by adding additional cross-product terms and also by subdividing the sample. For the empirical specification of (2) for people having completed their schooling, B is measured by IQ, $I T_{i}$ by years of schooling obtained, and $\Sigma R_{1}$, market inputs of the school, by the measures of quality of the colleges attended. The quality measures represent features of educational institutions which are costly.

$$
{ }^{23} \text { That is, } \sum_{i=1}^{t} \Delta H_{i}=H_{t} \text {. }
$$


It is difficult to measure the output units of this "human capital production function," which are really units of productive skills acquired in school. We will see below that this is not a problem.

The human capital earnings function asserts that current period income $\left(Y_{t}\right)$ equals the sum of those earnings obtainable without any investment in human capital $\left(Y_{0}\right)$ and those earnings obtained as a return on human capital acquired up to that point in the individual's iffe. Formally.

$$
Y_{t}=Y_{0}+r H_{t}+u
$$

In (3), I is the rate of return to units of human capital accumulated in all periods up to $t$.

The focus of this study is on the relationship between earnings and the human capital production function relevant to schooling. This relationship can be explored by estimating empirically the reduced form obtained by substituting (2) into (3), to get

$$
Y_{t}=Y_{0}+r\left(\alpha \Sigma R_{1}+B \Sigma T_{1}+B\right)
$$

Note that we cannot interpret the coefficients on years, IQ and quality as rates of return since the coefficients are equal to $r$ times a weighting factor. The formulation of (4) used in the empirical section below to study people no longer in school is:

$$
\begin{aligned}
\ln Y_{t}=\ln Y_{0} & +a \operatorname{EXP}+b \operatorname{EXPSQ}+c Y R S+d I Q \\
& +\operatorname{QUAL}+f_{1} V_{1}+u
\end{aligned}
$$


In $Y_{t}$ is $\log$ of 1969 earnings, ExP is years of experience in the full-time labor force (years since first fob), and EXPSQ 18 the squared value of EXP to take account of the nonlinear influence of on-the-job training on earnings. $^{24}$ YRS $1 \mathrm{~s}$ years of schooling. IQ is a measure of the level of ability (presumably affected by a combination of genetics and environment) and QUAL is a measure of the quality of college attended (institutional inputs or traits of one kind or another). The last three factors are important since in part they determine the amount of human capital acquired through schooling and hence (indirectly) affect earnings. 25 $V_{1}$ are several occupational dumies. The occupational dummies were particularly necessary, since teachers are traditionally paid less than other people with the same education (sometimes allegedly because of nonpecuniary benefits) and doctors receive more. The overrepresentation of highly paid but relatively low educated pllots was also controlled for.

24 see B. Chiswick, "Interregional Analysis of Income Distribution," for the development of a model which requires the dependent variable to be $\log$ of earnings and both EXP and EXPSQ as independent variables. Also see J. Mincer, "The Distribution of Labor Incomes: A Survey with Special Reference to the Human Capital Approach," Journal of Economic Literature, March 1970.

25

obviously

$$
\begin{aligned}
& \frac{\partial Y_{t}}{\partial Q}=\frac{\partial Y_{t}}{\partial H} \cdot \frac{\partial H}{\partial Q} \cdot \text { We are able to estimate } \\
& \frac{\partial Y_{t}}{\partial Q} \text { but not } \frac{\partial Y_{t}}{\partial H} \text { or } \frac{\partial H}{\partial Q} \text {. }
\end{aligned}
$$


The $v_{1}$ 's can also stand for other variables like health, location, socioeconomic background, etc. In some of the estimates.

The quality measure used in this section is that for the last college attended by the respondent. This particular form of the quality variable was selected, since it appeared in preliminary work that those who went to more than one college (for example, graduate school) had incomes affected primarily by the nature of their final college. 26

For these regressions, a variable was devised as the $Q_{U G}$ for those not going on, and $Q_{\text {GRAD }}$ for those with more than four years of college. This enables a single average "Income elasticity" of college quality and ignores different payoffs to quality depending upon years. This 1s somewhat less cumbersome to deal with than two separate variables, although It will be seen that the quality coefficients do differ depending upon attainment.

26 For those with thirteen or more years of schooling the following equation was estimated:

$$
\ln x_{69}=a+b Q_{U G}+c z \cdot Q_{U G}+d Q_{G R A D}+e_{i} v_{1}+u_{1}
$$

where $\mathrm{z}=1$ if years of education was 13 to 16 inclusive and 0 otherwise, $Q_{U G}$ and $Q_{\text {GRAD }}$ are measures of undergraduate and graduate college quality, respectively and $v_{i}$ are other variables like ability, years of education, experience, and several occupational dumenies. With this formulation the coefficients $c$ and $d$ were significant (t-tests) but b was not. The implication is that undergraduate quality matters only for those who do not go beyond four years of college. In some of the estimates below e QUAL was replaced by $f Z \cdot Q_{U G}+9 Q_{\text {GRAD }}$ where $z=1$ if years of education was 13 to 16 inclusive and 0 otherwise. 
III. The Empirical Estimates

This study only considers those with at least some college. For purposes of some of the work reported below, individual's were included in the regressions only if they attended colleges for which all the quality measures were available. This was done so that comparisons between different quality measures in the regressions would not be clouded by varying degrees of freedom. (We would have to eliminate individuals in particular regressions when the quality measure was not available for their schools, or the computer would assign a value of zero to quality which is wrong.) There were 1,511 people in this sample.

The question arises whether this biases the study due to the particular types of schools remaining for which all the quality data are available. Biases would exist if one particular quality of school refused information. At first glance, one might predict that schools of low quality would be the ones reluctant to report. However this is not generally true. Many schools provide the services of granting college educations and degrees to high school graduates who are not qualified to enter schools generally considered to be high quality institutions. It is in the interest of these low quality schools to become known by less qualified college aspirants. On the other hand, a number of schools with "good reputations" may be reluctant to report statistics for fear of revealing quantitative evidence that their reputations may not be fully justified. Hence there appear to be reasons why both high and low quality schools would not report. Some schools may have 
other reasons, unrelated to quality, for not reporting. For example, some schools only require S.A.T. scores from lower quality applicants (those graduating in the bottom 75 per cent of their high school classes must report S.A.T.). Some schools might not feel that their avallable data are relevant, as when most faculty members are only part-time employees of the college. Other school wight not want to take the time to compute the data desired. There is no reason why these nonreporters should fall into any particular quality group, and the evidence confirms this. 27

A potentially more serlous problem with the quality data is that most of the information on schools is for the post-1960 period, whereas the respondents attended around 1950. Unfortunately, earlier data on colleges are not available; schools have been willing and able to use computers to make information available only in recent times. The assuraption is that the correlation of college quality is unchanged over time. This assumption is probably not too bad particularly in a gross sense (good schools are still good but the ranking of the good schools might vary somewhat).

One of the few sets of data on college attributes available over a reasonable period of time is those on average salary. Data for 36

27 The colleges remaining in our sample range from the very top to the very bottom of each of the quality measures. However, the 1,511 individuals left for our study appear to have somewhat higher incomes, years of schooling and ability than the full sample with thirteen or more years. Some implications of this and comparisons with less restricted samples will be described below. 
schools were made available to me for the years 1939-40, 1953-54, 1959-60, and $1969-70 .^{28}$

Several tests were performed and these revealed significant serial rank correlation. Analysis of vaxiance revealed that the variation of rank across schools at each point in time was significantly greater than the variance of rank of a school over time. ${ }^{29}$ Table 4 reveals the Spearman Rank Correlation Coefficients and tests of significance for values of average salary in particular years. Both tests indicate a strong tendency for schools to be of roughly the same rank quality over time.

It will be shown below that the quality measures for later periods are highly correlated with earnings of those who attended earlier. One is tempted to argue that if quality measures for the more relevant year were obtainable, these would reveal an even stronger relationship with earnings. However, the question of effects of college quality are too important to put aside on the grounds that current data are imperfect. ${ }^{30}$

28

These were obtalned through the generous cooperation of Mrs. M. Eymonerie of the American Association of University Professors, Washington, D.C. The thirty-six schools were not identified specifically but represent a cross section of American colleges.

${ }^{29}$ The F-ratio was 12.43 and the critical $F$ for the given degrees of freedom for significance at the 1 per cent level is 1.99

30

It has been suggested that if graduates from certain colleges earned high incomes for reasons unrelated to our quality measures, they might have subsequently donated large sums to their Alma Mater. This would have enabled colleges to then obtain high marks in our quality measures. In this case high incomes supported high quality. Moreover high current incomes might be due to current prestige of ones Alma Mater regardless of the quality during the time attended. 
TABLE 4

Tests of Serial Correlation of Average Faculty Salary

\begin{tabular}{ccc}
\hline Years Compared & $\begin{array}{c}\text { Spearman Rank } \\
\text { Correlation } \\
\text { Coefficient }\end{array}$ & $\begin{array}{c}\text { Significance } \\
(26 \text { DF) }\end{array}$ \\
\hline $1939-40$ and $1953-54$ & .6759 & 4.6772 \\
$1939-40$ and $1959-60$ & .8100 & 7.0447 \\
$1939-40$ and $1969-70$ & .5500 & 3.3586 \\
$1953-54$ and $1959-60$ & .8752 & 9.2251 \\
$1953-54$ and $1969-70$ & .7099 & 5.1396 \\
$1959-60$ and $1969-70$ & .7777 & 6.3097 \\
\hline
\end{tabular}


For graduate departments there have been periodic ratings of quality since 1925. We selected studies made in 1925, 1957, and 1969. We then aggregated department rankings to give each of the schools that appeared in all three rankings an overall institutional ranking for each year. We then took rank correlations of the school standings over time. It appears that the correlations between rankings in 1969 and 1957 and the correlation between rankings in 1957 and 1925 both were approximately .7. The correlation between rankings in 1969 and 1925 was .54. Hence, it appears that even over long periods of time institutional quality has been roughly constant. These rankings of graduate schools over time appear in Table 5. Table 6 provides the estimation of earnings functions with different quality measures. It appears that regardless of how quality is measured, the traits of one's school significantly affect the log of subsequent earnings (1.e., log of 1969 earnings). These affects are after controlling for the individual's IQ, years of education and experience. The $t$-values on quality (ten measures) range from 3.744 to 6.049 with 1,506 degrees of freedom. Here we use a single variable--the quality of last college attended (graduate or undergraduate where appropriate). We should pause at this point to note that the coefficient on years of schooling is only slightly over .03 in all the earnings functions of Table 6 . These coefficients should not be interpreted as the rate of return to years of education. According to the theory of human capital it can be shown that the rate of return to years of schooling equals the 
TABLE 5

Rankings of Graduate Institutions Over Time

\begin{tabular}{|c|c|c|c|c|c|c|}
\hline & \multicolumn{3}{|c|}{ Total Overall Rankings } & \multicolumn{3}{|c|}{ Serial Correlations } \\
\hline & 1969 & 1957 & 1925 & $1969-57$ & $1957-25$ & $1969-25$ \\
\hline Harvard & 1 & 1 & 2 & .69822 & .69286 & .53572 \\
\hline Berkeley, California & 2 & 2 & 9 & & & \\
\hline Yale & 3 & 3 & 5 & & & \\
\hline Stanford & 4 & 13 & 14 & & & \\
\hline Chicago & 5 & 6 & 1 & & & \\
\hline Princeton & 6 & 7 & 6 & & & \\
\hline Michigan & 7 & 5 & 8 & & & \\
\hline Wisconsin & 8 & 8 & 4 & & & \\
\hline Cornell & 9 & 9 & 10 & & & \\
\hline Columbia & 10 & 3 & 3 & & & \\
\hline Johns Hopkina & 11 & 15 & 7 & & & \\
\hline Illinois & 12 & 10 & 11 & & & \\
\hline Pennoylvania & 13 & 11 & 12 & & & \\
\hline Indiana & 14 & 14 & 15 & & & \\
\hline Minnesota & 15 & 12 & 13 & & & \\
\hline
\end{tabular}

The list of schools includes only those fifteen which were ranked in all three of the years.

Sources: 1925: R. Hughes, "Report of the Comenittee on Graduate Instruction," Educational Record, 15 (Apr: 192-234)

1957: K. Keniston, Graduate Study and Research in the Arts and Sciences at the University of Pennsylvania (Phil, University of Pennsylvania Press, 1959).

1969: Roose, K.D., and Anderson, C.J., A Rating of Graduate Programs, Washington, D.C.: American Council on Bducation, 1970. 
coefficient on years, $r \cdot \frac{1}{k}$, where

$$
k=\frac{\text { Actual opportunity costs }+ \text { direct costs }}{\text { Annualized opportunity cost }}
$$

Hence the coefficient on years is the (private) rate of return only if $k=1$. Actual opportunity costs equal annualized opportunity costs less the amount that a student earns, perhaps when schools are closed during the summer. If direct costs exactly equal student earnings, exactly 100 per cent of potential income would be invested in obtaining human capital, $k$ would equal 1 since both numerator and denominator have been reduced to annualized opportunity costs, and $r$ would be the rate of return per year of attendance at an average quality school by a student of average ability. Our sample contains people who almost always went to college under the G.I. Bill of Rights. These students had no direct costs of schooling and received subsistence payments as well. As an approximation we assume that, as students, our sample members received $\$ 100$ per month plus tuition under the G.I. Bill. ${ }^{31}$ From the 1950 Census we can deduce that an average white high school graduate between the ages of 25 and 29 earned \$3,008 per

${ }^{31}$ President's Commission on Veterans Payments, The Historical Development of Veterans Benefits in the U.S., G.P.0. 1956, p. 156. The Servicemen's Readjustment Act, known as the G.I. Bill of Rights passed in the 78th Congress 1944, paid up to $\$ 500$ per year tuition plus $\$ 50$ per month with no dependents, or $\$ 75$ per month with one or more dependents. In 1945 the monthly payments with one or more dependents was raised to $\$ 90$ and in 1948 was raised to $\$ 105$ with one dependent and $\$ 120$ with more than one dependent. 
year on average. 32 This was assumed to be the foregone earnings of people in the sample. Hence 1 appears that $k$ equals roughly .35106 and $\frac{1}{k}$ equals $2.85 .^{33}$

In order to estimate rates of return to years in college, we should multiply the years coefficient by 2.85 . The rates of return appear to be roughly 9.7 per cent. Gary Becker estimated the returns to a white male college graduate to be 13 per cent in $1949 .^{34}$

There are several reasons why the present estimates are below those of others. First, our sample includes only people who have at least some college education; and so, our coefficients reflect the return to an extra year of college not the return to college training compared to the return to high school attendance. The second reason for the low rates of return to higher education (relative to previous studies) is the preponderance of teachers in our sample. Teachers have high education and relatively low annual earnings. This exception is noted explicitly in some of the later

\footnotetext{
${ }^{32}$ Census of Population, 1950, Special Report P.E. 5B, Education, G.P.O., 1953.

${ }^{33}$ Assuming a nine month school year, $k=\frac{3 / 4 \cdot 3008-1200}{3008}=.35106$.
} The crudeness of this assumption should be obvious.

${ }^{34}$ G.S. Becker, Human Capital, National Bureau of Bconomic Research, 1964. Although Becker acknowledges the crudeness of his estimate, it has been widely cited. Although there is some reason to believe that the present estimate is more accurate, since we were able to control explicitly for more factors, we should not axgue too strongly on this point except perhaps to say that Becker's estimates of the returns to a college degree might be a bit too high. Our estimates are very crude also. 
regression estimates. Finally, an examination of the drop outs in our sample Indicates that they were usually pulled out of school by good earnings opportunities, not pushed out due to poor achievement.

Another reason for the apparent low pay off to extra "raw years" in school is that we are controlling for college quality. It is probably the case that those with more years also attended higher quality institutions. 35 Thus part of the return to extra years is reflected in returns to quality rather than returns to years. The coefficient on years rises to slightly over .04 when quality variables are omitted from the earnings functions; and this would imply a rate of return to years not controlling for quality of about 12 per cent. Of course, the ability variable also detracts from the coefficient on years, since there is a positive relationship between innate ablity and educational attainment. 36

After establishing that quality is important, however measured, the task of inferring which aspect of quality is most important is more difficult. The question we are ralsing here is not the rate of return to different types of college quality, but, more simply, the effect of certain aspects of quality on income. Here we are looking at the significance of

${ }^{35}$ The correlation between years and quality of the last school attended is about . 25 .

${ }^{36}$ Taubman and Wales (in press) estimate an upward bias in the coefficient on years when the $I Q$ is omitted of about 30 per cent. This depends on the specification of their model and on the particular measure of $I_{Q}$ used. 
the coefficients on quality in regressions which explain differences in individual incomes; later we make an attempt to estimate rates of return to quality. Table 6 shows that average faculty salary has the highest $t$-value, closely followed by the average S.A.T. scores of entering freshmen and Astin's measures of intellectuality and selectivity. One is tempted to conclude that faculty quality and peer group effects are the most important (In terms of subsequent earnings) features of college quality. The peer group effects are in line with the conclusions of James Coleman in the study of lower levels of education. 37

The $R^{2}$ in the earnings function before adding the quality variable was .0602 . The addition of the average salary variable raises the $R^{2}$ by .0223 to .0825 . Once again, the quality variables measuring student characteristic add the next largest amounts to $R^{2} \cdot 38$ Interestingly, according to the $t$-test and the addition to $R^{2}$ criteria, the income and expenditures for a full-time equivalent student are the least important quality variables. The Gourman statistics which purport to take all

${ }^{37} \mathrm{~J}$. Coleman, et al, Equality of Educational Opportunity, Washington, G.P.O. 1966.

${ }^{38}$ It has been suggested that the average college S.A.T. variable might be a better proxy for the innate ability of the particular student than is the ability variable that we use. The average S.A.T. variable may be picking up ability traits of the individual not captured by our individual ability measure. If this were the case, the suggestion of a peer group effect would be wrong. To really confirm the peer group effect requires both Individual and college S.A.T. scores but we lack the former. It would also be useful to have variance of S.A.T. by college which is not available. 


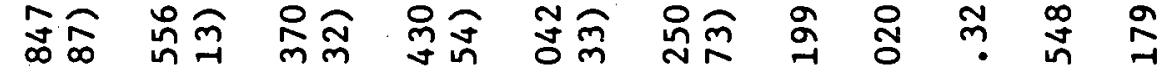
-iơ

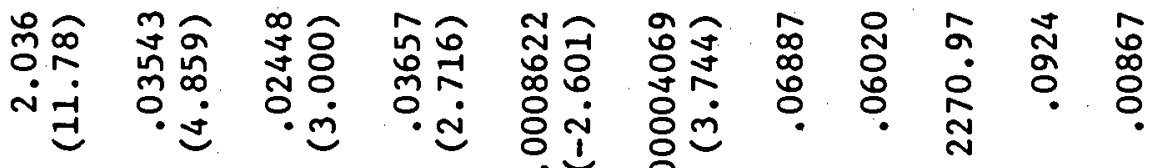
究 出斗㸵甾

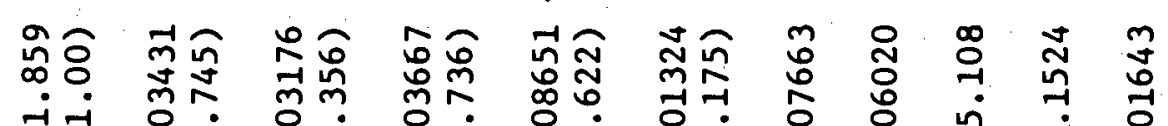
-

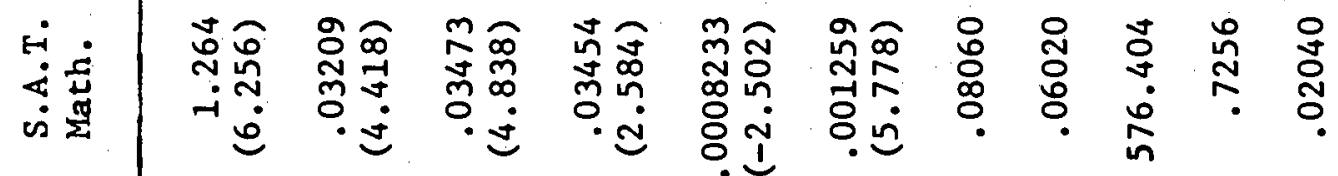

ค่

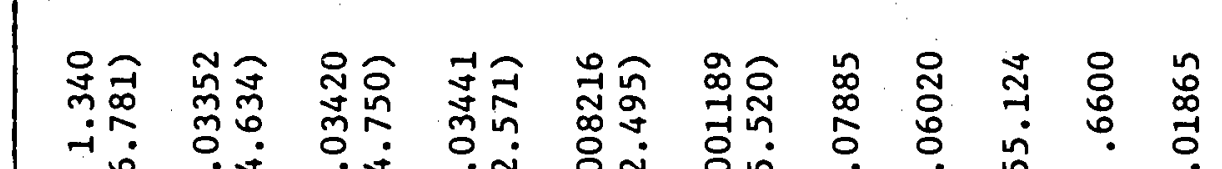
山े

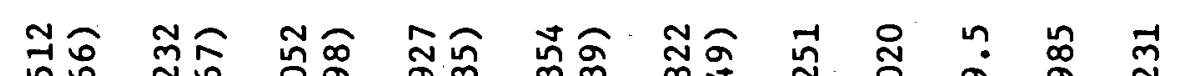

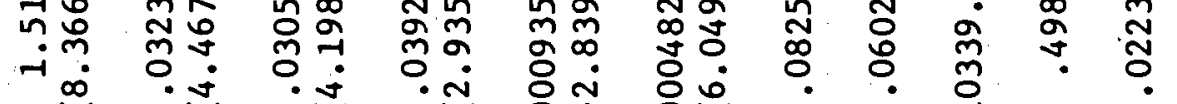
O 足

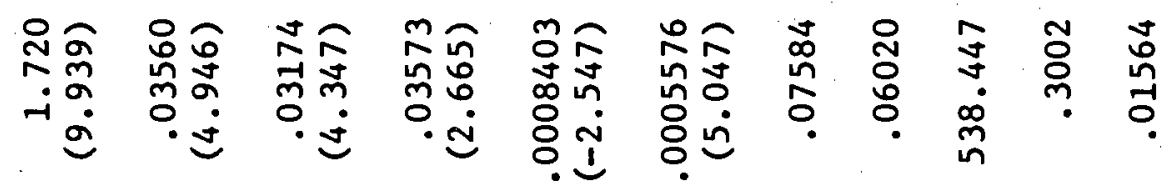

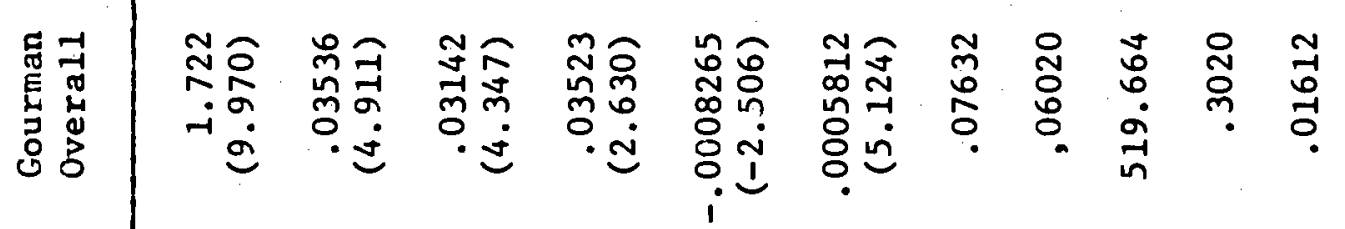

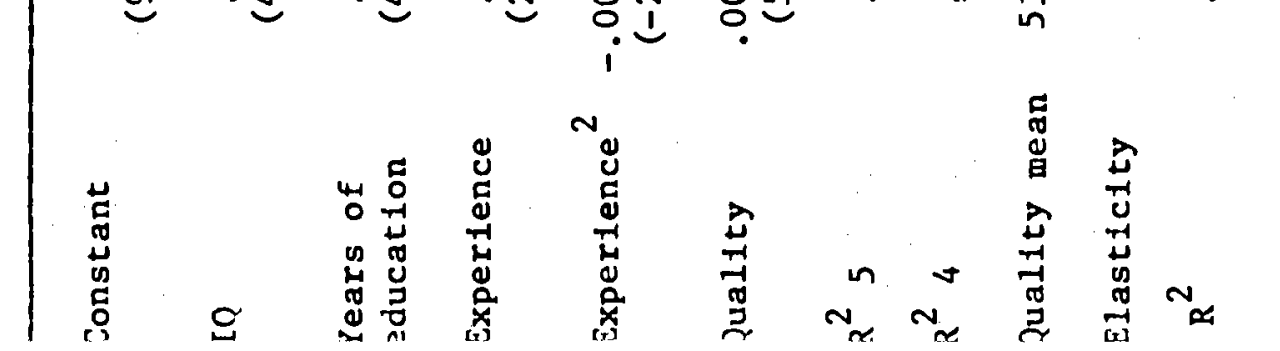


factors into account, fall somewhere between the power of the faculty and student quality measures, and the expenditure measures.

The relative weakness of the expenditure data might be explained by the fact that they are deflated by the number of full-time equivalent students. Indeed, average faculty salary, a prime component of expenditures, is the most powerful measure of quality. Welch has argued that for state elementary and high school systems, size is a factor having a significant positive effect on earnings; that is, an important aspect of school quality as we define quality. ${ }^{39}$ If colleges enrolling a large number of students are of higher quality than colleges enrolling fewer students, then the expenditure data deflated are actually ratios of two factors, each a positive influence on earnings. If expenditures per student are high because expenditures are high, holding constant size of college, we would expect a strong positive relationship with later earnings. On the other hand, if the variable is large because the number of students is small, holding expenditures constant, we would expect a negative relationship between the ratio and income. In a large sample of schools, the expenditures per student probably vary for both reasons and so the over all effect is blurred. Another reason to suspect that the expenditures per student data will not correlate highly with income of graduates is that only part of each dollar spent finds its way into

39 F. Welch, "Measurement of the Quality of Schooling," American Economic Review, May 1966, p. 379. 
projects which makes students more productive (1.e. what value is there to earning ability of gardening expenses for the college greenery). of course, a happier student may learn more and hence earn more.

We can calculate a quality elasticity of income--the percentage change in income for a percentage change in quality. However, these elasticities cannot be used to compare impacts of quality. A 1 per cent change in average S.A.T. level is not comparable to a 1 per cent change in average salary. These elasticities are presented in Table 6 (second line from the bottom). If we could calculate the cost of a 1 per cent change in each of the quality measures, only then could we see the returns to each. This will be attempted later in this paper. Table 7 presents two specifications of the earnings equation which include more than one quality variable. In the first, it is evident that average salary and S.A.T. scores have separate and statistically significant influences on income. The second version shows that when additional types of quality measures are added, the importance of faculty salaries and average S.A.T. scores still stand out, but the other variables add nothing extra statistically. It appears that two separate and important aspects of quality can be identifled, namely, faculty quality and peer group (student) effects. 40

40 As stated earlier, the significance of the average S.A.T. scores might be measuring the effects of students' own abilities not captured by IQ. However, there seems to be no reason why 1963 S.A.T. scores would better represent ability than would the ability measures taken in the Air Force usually before college attendance. Other variables used to measure quality apparently relate to income only as proxies for the same effects measured by faculty salaries and average S.A.T. scores. Of course, it might be that other aspects of quality are important but are omitted from our model or are merely poorly measured. 
TABLE 7

Earnings Functions with Several quality Variables

\begin{tabular}{|c|c|c|}
\hline Constant & $\begin{array}{r}1.332 \\
(6.761)\end{array}$ & $\begin{array}{r}1.300 \\
(5.665)\end{array}$ \\
\hline IQ & $\begin{array}{r}.03105 \\
(4.285)\end{array}$ & $\begin{array}{r}.03099 \\
(4.265)\end{array}$ \\
\hline Years of education & $\begin{array}{r}.03053 \\
(4.206)\end{array}$ & $\begin{array}{l}.03055 \\
(4.190)\end{array}$ \\
\hline Experience & $\begin{array}{r}.03781 \\
(2.827)\end{array}$ & $\begin{array}{r}.03766 \\
(2.310)\end{array}$ \\
\hline Expertence $^{2}$ & $\begin{array}{l}-.0009073 \\
\quad(-2.756)\end{array}$ & $\begin{array}{r}-.0009029 \\
(-2.736)\end{array}$ \\
\hline Average salary & $\begin{array}{r}.00003392 \\
(3.343)\end{array}$ & $\begin{array}{r}.00003342 \\
(2.108)\end{array}$ \\
\hline S.A.T. verbal & $\begin{array}{r}.0006215 \\
(2.272)\end{array}$ & $\begin{array}{r}.0005807 \\
(1.848)\end{array}$ \\
\hline $\begin{array}{l}\text { Expend1tures: Inst. } \\
\text { Dept., Res., Library }\end{array}$ & & $\begin{array}{r}-.00001069 \\
(-0.2147)\end{array}$ \\
\hline Astin selectivity & & $\begin{array}{r}.001087 \\
(0.3269)\end{array}$ \\
\hline Gourman academic & & $\begin{array}{r}.00001541 \\
(.07664)\end{array}$ \\
\hline$R^{2}$ & .08564 & .08573 \\
\hline
\end{tabular}


IV . The Interaction Between Years of Schooling and College quality

To measure college quality's impact by the characteristics of the last college attended by an individual is a useful technique to provide answers to questions about the relative importance of various college attributes and changes in these importances over an individual's life cycle. However, it appears that quality does indeed have a differential effect depending upon the number of years of schooling obtained. Since this is the case, we must give more attention to the particular specification of the earnings functions which include measure of college quality.

Table 8 reestimates the earnings functions for six of the cases reported earlier. The earnings function in this case inserts a measure of undergraduate quality for those with sixteen or fewer years of schooling and a measure of graduate quality for those who attended graduate school. In this case, the results are similar to the earlier ones except it appears that undergraduate quality is more important for those with sixteen or less years of schooling than is graduate quality for those who go on. 41 The coefficients on $Q_{U G}$ were higher and the $t$-tests

${ }^{41}$ positive correlation between $Q_{U G}$ and $Q_{\text {GRAD }}$ for those with more than sixteen years implies the coefficient on graduate quality is higher than it would be if $Q_{U G}$ were entered for those with more than sixteen years. When this was done the $Q_{U G}$ variable was not significant for those with more than sixteen years. On the other hand, several individuals attended graduate schools for which average faculty salary and average S.A.T. scores were not available. Hence, in those cases the $Q_{\text {GRAD }}$ appears as 0 and this tends to lower the slope of the graduate quality coefficients in these two cases. 


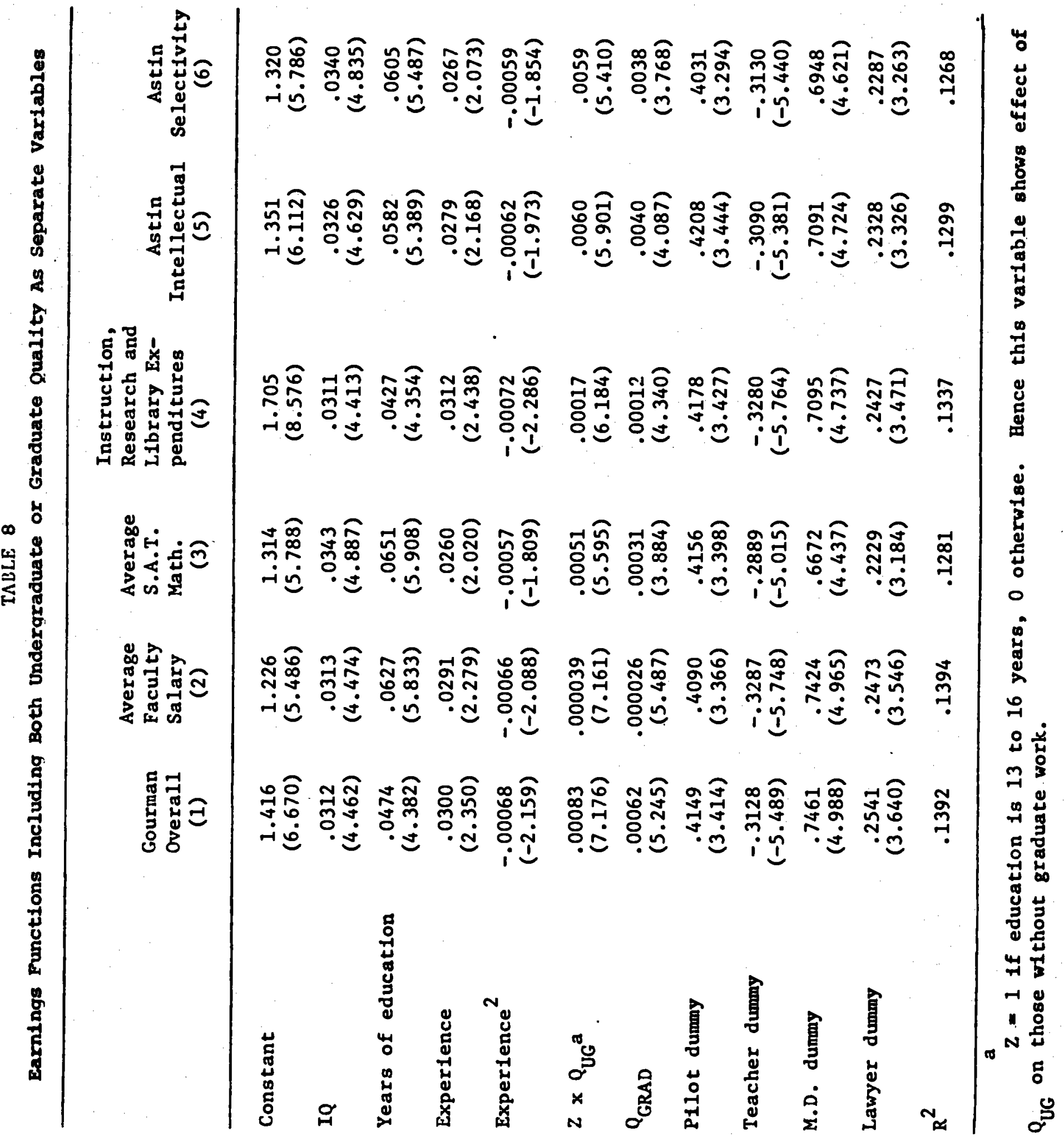


more significant in all cases compared to $\mathcal{Q}_{\mathrm{GRAD}}$. Since quality appears to affect differently those who did and those who did not go on to graduate school, we are led to subdivide the sample further. 42 since the quality effects differed by years of attainment, it is logical to run separate earnings functions for those with sixteen or less years of schooling and for those with seventeen or more years. This was done in Table $90^{43}$ In only one case reported in Table 4 (Gourman--larger, less exclusive sample) was undergraduate quality statistically significant for those who went on to graduate school. However, in almost all cases, impact of the last quality was greater (or equal) for those with more years; clearly the effects of quality appear greater for this group if we combine effects of undergraduate and graduate quality. These results are at odds with those presented in Table 8, where the impact of quality was greater for those with sixteen or less years. However, in the specification used in Table 9 we are no

42 The second change in the specification of Table 8 is that four dumy variables wore inserted to account for "occupations." These serve to increase the coefficient on years for reasons elaborated upon elsewhere. Pilots had low education and high earnings, whereas teachers generally had the reverse.

${ }^{43}$ Columns one through six in Table 9 contain only respondents who had data for all three quality measures--S.A.T., average faculty salary, and Gourman--for their undergraduate schools and for their graduate school. if they attended. Columns 7 through 10 contain a larger sample, omitting only those without Gourman and expenditure data. The larger sample had a lower mean IQ and lower average "Gourman" quality schools. It is interesting to note that the lower quality sample revealed smaller impacts of college quality than did the more exclusive groups. This will lead us into our study of the interaction between ability and quality in the next section. 


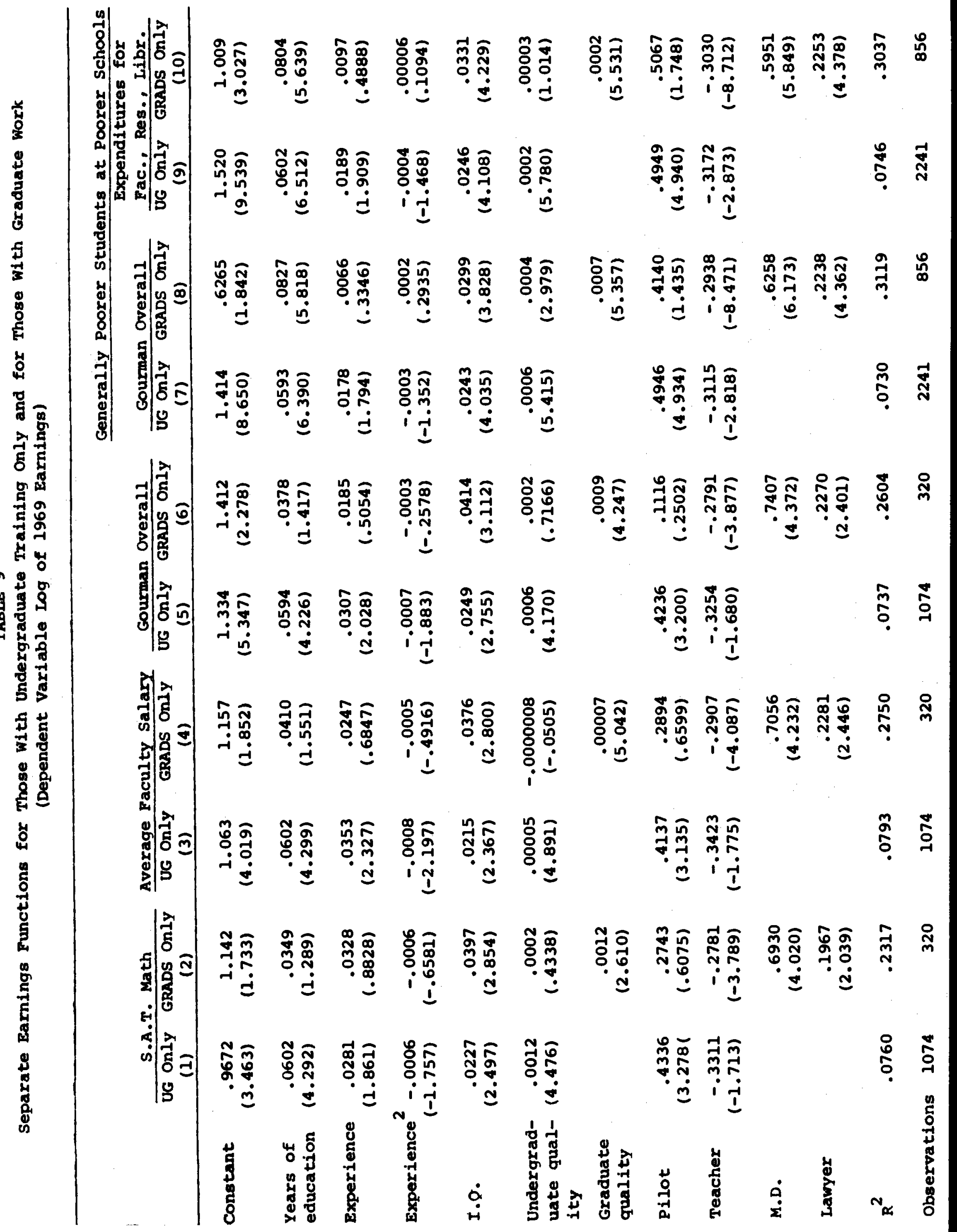


longer constraining the coefficients on other variables to be the same regardless of years attained, since we estimate different functions by years of schooling. We can also note that those with seventeen or more years probably were of the highest ability and so the interaction between IQ and quality is suggested.

It might be the case that the differences which are observed by comparing coefficients on most variables in Table 8 with those in Table 9 are not statistically significant. The question arises whether it is necessary to separate individuals by schooling attainment in order to estimate earnings functions--whether or not there are statistically significant differences in the functional forms according to the number of years obtained. Moreover, it is possible that structures might differ according to attainment of individuals separated more finely than merely between those with sixteen or fewer and seventeen or more years of schooling. In particular, we might suspect that the earnings function for those who have received a bachelor's degree differs from those who attended college but withdrew before obtaining the degree. To answer this type of question, CHOW tests were performed on the earnings functions presented in Table 10. Here we have earnings functions for those with fewer than sixteen years of schooling, exactly sixteen years of schooling, and more than sixteen years of schooling, along with an earnings function for the total sample. CHOW tests were performed by comparing the earnings functions structure of those with less than sixteen years with those people having sixteen years, and also by comparing 
TABLE 10

Earnings Functions for More Finely Separated Levels of Schooling Attainment

\begin{tabular}{|c|c|c|c|c|c|}
\hline & Ed. $<16$ & $\mathrm{Ed} .=16$ & Ed. $>16$ & Ed. $\leq 16$ & $13+$ \\
\hline Constant & $\begin{array}{r}1.735 \\
(5.758)\end{array}$ & $\begin{array}{r}2.344 \\
(.3109)\end{array}$ & $\begin{array}{r}.6265 \\
(1.842)\end{array}$ & $\begin{array}{r}1.414 \\
(8.650)\end{array}$ & $\begin{array}{r}1.476 \\
(10.53)\end{array}$ \\
\hline $\begin{array}{l}\text { Years of } \\
\text { education }\end{array}$ & $\begin{array}{r}.04055 \\
(2.060)\end{array}$ & & $\begin{array}{r}.08268 \\
(5.818)\end{array}$ & $\begin{array}{r}.0593 \\
(6.390)\end{array}$ & $\begin{array}{r}.0523 \\
(7.033)\end{array}$ \\
\hline Experience & $\stackrel{.10722}{(1.290)}$ & $\begin{array}{r}.01269 \\
(.7818)\end{array}$ & $\begin{array}{l}.006618 \\
(.3346)\end{array}$ & $\begin{array}{r}.0178 \\
(1.794)\end{array}$ & $\begin{array}{r}.0188 \\
(2.196)\end{array}$ \\
\hline Experience ${ }^{2}$ & $\begin{array}{r}-.0003489 \\
(1.093)\end{array}$ & $\begin{array}{r}-.0001129 \\
(.2634)\end{array}$ & $\begin{array}{r}.0001546 \\
(.2935)\end{array}$ & $\begin{array}{r}-.0003 \\
(-1.352)\end{array}$ & $\begin{array}{l}-.00033 \\
(-1.549)\end{array}$ \\
\hline I.Q. & $\begin{array}{r}.02792 \\
(2.870)\end{array}$ & $\begin{array}{r}.02049 \\
(2.685)\end{array}$ & $\begin{array}{r}.02988 \\
(3.828)\end{array}$ & $\begin{array}{r}.0243 \\
(4.035)\end{array}$ & $\begin{array}{r}.0277 \\
(5.707)\end{array}$ \\
\hline $\begin{array}{l}\text { Undergraduate } \\
\text { quality }\end{array}$ & $\begin{array}{r}.0004807 \\
(2.689)\end{array}$ & $\begin{array}{r}.0006584 \\
(4.932)\end{array}$ & $\begin{array}{r}.0004390 \\
(2.979)\end{array}$ & $\begin{array}{r}.0006 \\
(5.415)\end{array}$ & $\begin{array}{r}.00061 \\
(7.058)\end{array}$ \\
\hline $\begin{array}{l}\text { Graduate } \\
\text { quality }\end{array}$ & & & $\begin{array}{r}.0007075 \\
(5.357)\end{array}$ & & $\begin{array}{l}-.00006 \\
(-1.067)\end{array}$ \\
\hline Pilot & $\begin{array}{r}.5146 \\
(4.479)\end{array}$ & $\begin{array}{r}.4229 \\
(1.792)\end{array}$ & $\begin{array}{r}.4140 \\
(1.435)\end{array}$ & $\begin{array}{r}.4946 \\
(4.934)\end{array}$ & $\begin{array}{r}.4900 \\
(5.292)\end{array}$ \\
\hline Teacher & $\begin{array}{l}-.2344 \\
(1.106)\end{array}$ & $\begin{array}{l}-.3464 \\
(2.717)\end{array}$ & $\begin{array}{c}-.2938 \\
(8.471)\end{array}$ & $\begin{array}{r}-.3115 \\
(-2.818)\end{array}$ & $\begin{array}{r}-.3153 \\
(-8.642)\end{array}$ \\
\hline M.D. & 0 & 0 & $\begin{array}{r}.6258 \\
(6.173)\end{array}$ & & $\begin{array}{r}.6010 \\
(5.310)\end{array}$ \\
\hline Lawyer & 0 & $\begin{array}{r}1.248 \\
(2.645)\end{array}$ & $\begin{array}{r}.2238 \\
(4.362)\end{array}$ & & $\begin{array}{r}.2350 \\
(4.534)\end{array}$ \\
\hline $\mathrm{R}^{2}$ & .05060 & .05165 & .31190 & .0730 & .1300 \\
\hline Observations & 999 & 1242 & 856 & 2241 & 3097 \\
\hline $\begin{array}{l}\mathbf{R}^{2} \text { prior to } \\
\text { occupations }\end{array}$ & .04366 & .03292 & .26857 & .0608 & .1158 \\
\hline
\end{tabular}


those with sixteen or fewer years with those with more than sixteen years. In each case the null hypothesis is that the two functions being compared do not have statistically different structures. Comparing the function of those with fewer than sixteen years to those with exactly sixteen years we cannot reject the null hypothesis and so conclude that these two functions have the same structures in a statistical sense. However, when comparing those with sixteen or fewer years with those with more than sixteen years, the $F$ value exceeds its critical level and, hence, we are led to refect the hypothesis that the structures are the same. This suggests that the two earnings functions estimated for those with sixteen or fewer years and those with more than sixteen years do indeed differ statistically. 44

The important conclusion from this section is that the effects of quality and the other variables introduced in our earnings function differ according to whether or not post-graduate education is obtained. However, there is no need to separate individuals with no graduate work into groups depending on whether or not they obtained the bachelors degree. This leads us to accept the conclusion suggested by Table 9, namely, that the impacts of quality are greater for those with postgraduate training compared to those with sixteen or fewer years of schooling.

44 When comparing those with less than sixteen years to those with exactly sixteen years the calculated $F$ was .3576 and the critical $F$ was 1.84 at the 5 per cent level. Hence we cannot refect the null hypothesis and conclude that the two cases have the same structure. When comparing those with sixteen or fewer years to those with seventeen or more the calculated $F$ is 3.790 and the critical $F$ is 2.25 at the 1 per cent level. Hence we reject $\mathrm{H}_{\mathrm{O}}$ and include the two structures are different. 
However, in a few of our tests, we continue to estimate one earnings function for those with only undergraduate, and those with graduate training combined. In these cases, we see effects of quality when other variables are constrained to have the same (average) influence regardless of years attained.

v. Results at Different Points on the Iife Cycle

college quality, no matter how defined, does affect earnings twenty years after attending. It is also interesting to ask whether or not quality of college has an increasing or decreasing effect on earnings over time. To this end, we estimated earnings functions which include two quality variables--undergraduate college quality for those with sixteen or fewer years of schooling, and quality of graduate school for those who attended to explain $\log$ of 1969 income, $\log$ of 1955 income, and $\log$ of real income in the initial year of full-time employment. 45

A positive correlation between $Q_{U G}$ and $Q_{G R A D}$ for those with more than sixteen years implies the coefficient on graduate quality is higher than it would be if $Q_{U G}$ were entered for those with more than sixteen years. When this was done, the $Q_{U G}$ variable was not significant for those with more than sixteen years.

Three different quality measures are used: the Gourman Index, average faculty salary, and average level of S.A.T. math scores of

45 Since starting year differed among individuals, the first-year incomes had to be adjusted to account for year-to-year price level changes. 
entering freshmen. 46 The results appear as Table 5. The three 1969 regressions are comparable to columns 1, 3, and 5 of Table 3, where the quality last variable is not separated by years of attainment. Also, in Table 11 four occupational dumbies are inserted to account for exceptional income-schooling relationships. Pilots generally had high earnings considering their education. Teachers usually have much schooling and low incomes due to fewer hours and alleged non-pecuniary rewards. Doctors have high incomes, partially due to monopoly elements in their profession; however, the reason for high pay for lawyers is less clear. The average of coefficients on $Q_{U G}$ and $Q_{G R A D}$ is not much different than the comparable coefficients in Table 8.

It should be noted, however, that in terms of significance of the quality variables (t-tests or addition to $R^{2}$ ), the 1969 and 1955 results are rather similar. Moreover, IQ has roughly the same effects on earnings in both years, and for some reason the coefficient on experience is greater in 1955. Another difference is that the coefficient on years of education variable is smaller when using 1955 education. It should be noted that in 1955 respondents averaged about 6.6 years of experience.

${ }^{46}$ Individuals were eliminated unless all three appropriate quality measures were available for them. When the regression for Gourman was rerun not eliminating for absent S.A.T. or salary data, the sample was larger, of slightly lower $I Q$, and had slightly lower average college quality. In that case, for all three years both the $Q_{U G}$ and $Q_{G R A D}$ had smaller (but significant) coefficients. This indicates a positive interaction between IQ and school quality. 


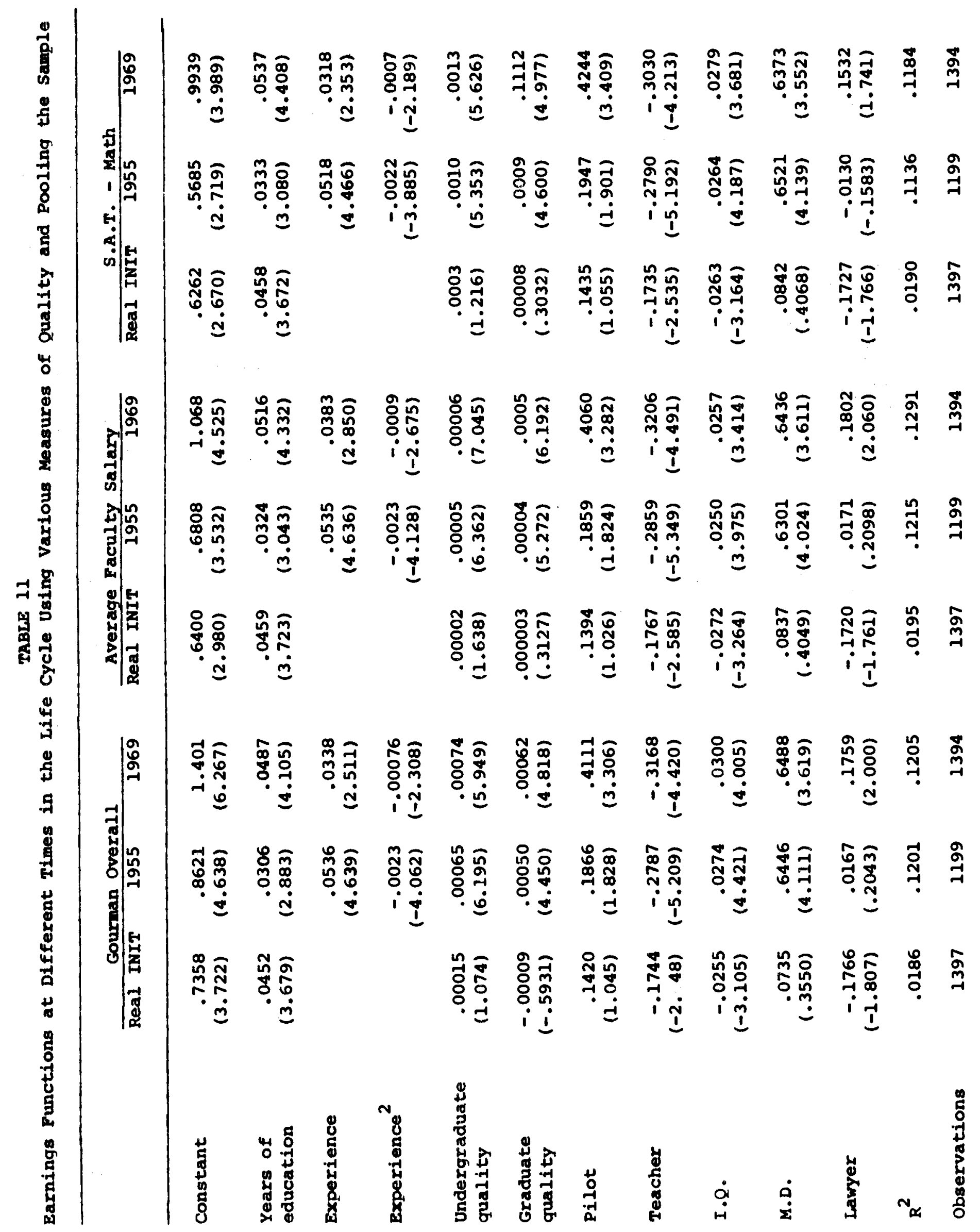


There is evidence that there is a positive relationship between years of education and investment in on-the-job training. It is likely that those with more years of schooling had been foregoing more earnings while investing on the job in the first few years of employment. However, by six years out, returns to all human capital acquired appear, and so differences in income by education are clouded. On the one hand more earnings are foregone by the more highly educated as they obtain more training. on the other hand, this group begins to reap returns to their human capital. The less educated group invests less in OJT (less income is foregone), but their earnings are lower.

Table 11 also shows earnings functions explaining income in the initial year of employment (when experience for each respondent was zero). Years of education still has a significantly positive effect with coefficients of over .045 . If the argument concerning the 1955 regressions were true, we would expect a negative relationship between income and years of schooling in the first year in the labor force. The argument is that the more educated person is investing further by giving up income to acquire on-the-job training. Here it appears the more educated earn more in the first year.

The IQ variable now becomes significantly negative, perhaps indicating a tendency for those more able to invest more on-the-job training in initial years in the labor force. If the relationship between ability and investment in on-the-job training is stronger than that between years of education and OJT, this might explain why the coefficient 
on years remains significantly positive in the initial year earnings functions. Moreover, to the extent that years of schooling serves as a credential, or screening device, to allocate those with more years into better paying first fobs (which still might provide on-the-job training), we would also expect a positive coefficient on years.

Another problem in comparing the earnings functions at different points in the life cycle is the differences in data reliability. The 1969 income data were obtained In a 1970 survey and the 1955 income was learned from a survey in 1955. However, the initial year's income was obtained by asking a "recall" question in 1969. The implication is that the initial year earnings figures are far inferior to those from the other two years studied.

Schooling quality is never statistically significant in the initial year earnings functions for either those with sixteen or fewer years or those with graduate training. It is apparent that the importance of college quality grows with experience in the labor force. One reason might be that students in better colleges are better prepared to benefit from on-the-fob training in their post-school lives.

Tables 12 and 13 reestimate the earnings functions for different points in the life cycle separately for individuals who attended sixteen or fewer years and for individuals who attended graduate school. Moreover, in these estimates education is defined as that education possessed by the individuals in 1955, and the occupational categories are also based on 1955 responses rather than responses obtained in 1969. Despite 
TABLE 12

Earnings Functions at Different Times in the Life Cycle Using Gourman Ratings and Dividing the Sample into Those With only Undergraduate Training and Those With Some Graduate Work

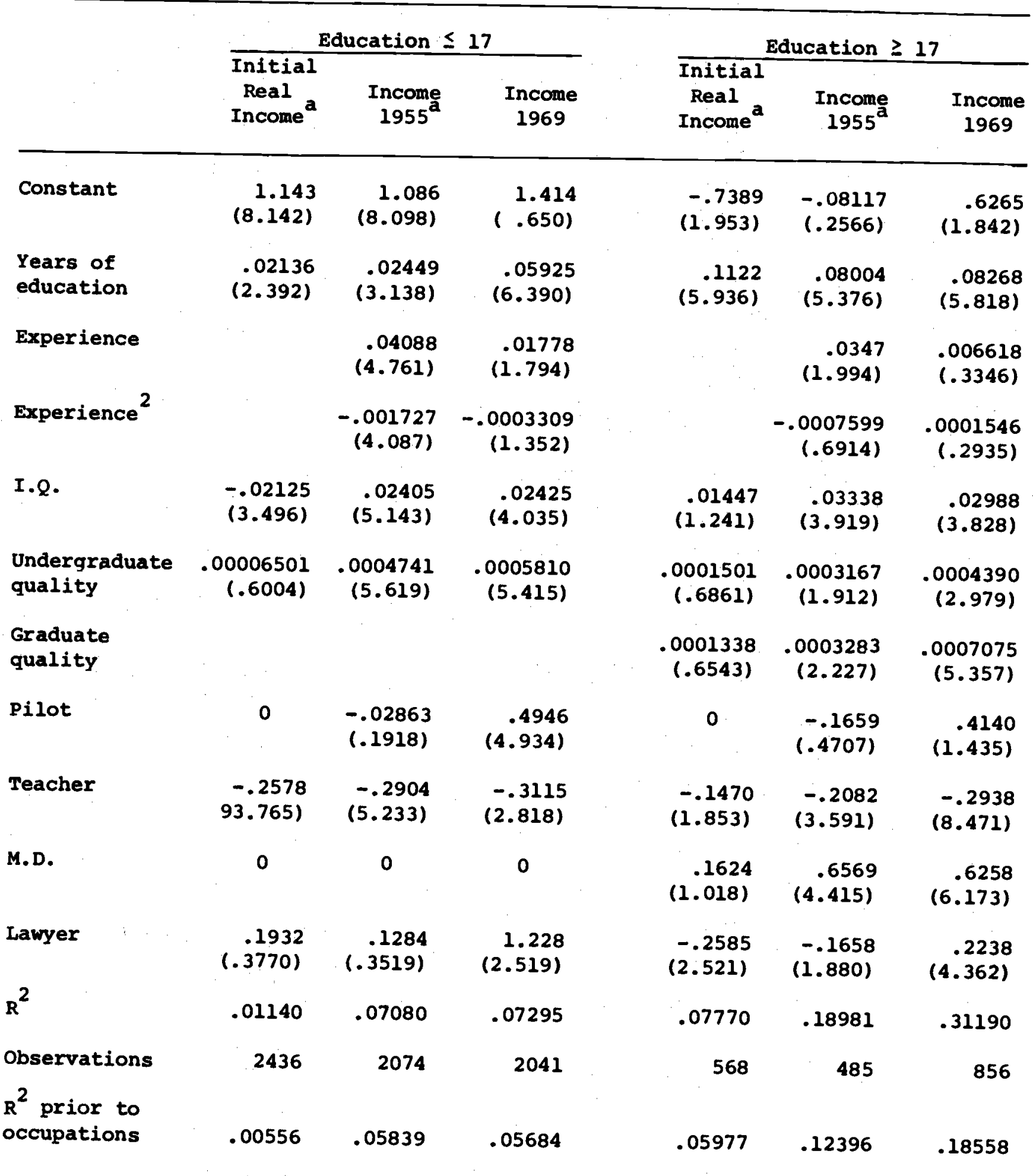

a Education and occupations in 1955 used in regression. 
TABLE 13

Barnings Functions at Different Times in the Life Cycle Using Expenditures on Faculty, Research, and Library and Dividing the Sample Into Those With Only Undergraduate Training and Those with Some Graduate Work

\begin{tabular}{|c|c|c|c|c|c|c|}
\hline & \multicolumn{3}{|c|}{ Education $\leq 17$} & \multicolumn{3}{|c|}{ Education $\geq 17$} \\
\hline & $\begin{array}{l}\overline{\text { Initial }} \\
\text { Real } \\
\text { Income }\end{array}$ & $\begin{array}{c}\text { Income } \\
1955^{8}\end{array}$ & $\begin{array}{c}\text { Income } \\
1969\end{array}$ & $\begin{array}{l}\text { Initial } \\
\text { Real } \\
\text { Income }\end{array}$ & $\begin{array}{r}\text { Income } \\
1955^{\mathrm{a}}\end{array}$ & $\begin{array}{c}\text { Income } \\
1969\end{array}$ \\
\hline Constant & $\begin{array}{r}1,149 \\
(8.463)\end{array}$ & $\begin{array}{r}1.185 \\
(9.025)\end{array}$ & $\begin{array}{r}1.520 \\
(9.539)\end{array}$ & $\begin{array}{c}-.6360 \\
(1.799)\end{array}$ & $\begin{array}{r}.1886 \\
(.6351)\end{array}$ & $\begin{array}{r}1.009 \\
(3.027)\end{array}$ \\
\hline $\begin{array}{l}\text { Years of } \\
\text { education }\end{array}$ & $\begin{array}{r}.02132 \\
(2.394)\end{array}$ & $\begin{array}{c}.02539 \\
(3.259)\end{array}$ & $\begin{array}{r}.06022 \\
(6.512)\end{array}$ & $\begin{array}{r}.1111 \\
(5.890)\end{array}$ & $\begin{array}{r}.07666 \\
(5.171)\end{array}$ & $\begin{array}{r}.08042 \\
(5.639)\end{array}$ \\
\hline Experience & & $\begin{array}{r}.04153 \\
(4.838)\end{array}$ & $\begin{array}{r}.01891 \\
(1.909)\end{array}$ & & $\begin{array}{r}.03390 \\
(1.904)\end{array}$ & $\begin{array}{l}.009719 \\
(.4888)\end{array}$ \\
\hline Experience ${ }^{2}$ & & $\begin{array}{r}-.001763 \\
(4.171)\end{array}$ & $\begin{array}{r}-.0003591 \\
(1.468)\end{array}$ & & $\begin{array}{r}-.0007280 \\
(.6615)\end{array}$ & $\begin{array}{r}.00005794 \\
(.1094)\end{array}$ \\
\hline$I \cdot Q$ & $\begin{array}{c}-.02175 \\
(3.589)\end{array}$ & $\begin{array}{l}.02442 \\
(5.239)\end{array}$ & $\begin{array}{r}.02457 \\
(4.108)\end{array}$ & $\begin{array}{r}.01454 \\
(1.252)\end{array}$ & $\begin{array}{c}.03510 \\
(4.143)\end{array}$ & $\begin{array}{r}.03311 \\
(4.229)\end{array}$ \\
\hline $\begin{array}{l}\text { Undergraduate } \\
\text { quality }\end{array}$ & $\begin{array}{r}.00002737 \\
(1.036)\end{array}$ & $\begin{array}{c}.0001162 \\
(5.620)\end{array}$ & $\begin{array}{r}.0001521 \\
(5.780)\end{array}$ & $\begin{array}{r}.00004765 \\
(.9499)\end{array}$ & $\begin{array}{c}.00002114 \\
(.5667)\end{array}$ & $\begin{array}{r}.00003456 \\
(1.014)\end{array}$ \\
\hline $\begin{array}{l}\text { Graduate } \\
\text { quality }\end{array}$ & & & & $\begin{array}{r}.00001057 \\
(.2529)\end{array}$ & $\begin{array}{r}.00008467 \\
(2.839)\end{array}$ & $\begin{array}{r}.0001549 \\
(5.531)\end{array}$ \\
\hline Pilot & 0 & $\begin{array}{r}-.01479 \\
(.09911)\end{array}$ & $\begin{array}{r}.4949 \\
(4.940)\end{array}$ & 0 & $\begin{array}{c}-.06360 \\
(.1813)\end{array}$ & $\begin{array}{r}.5067 \\
(1.748)\end{array}$ \\
\hline Teacher & $\begin{array}{c}-.2578 \\
(3.767)\end{array}$ & $\begin{array}{c}-.2913 \\
(5.251)\end{array}$ & $\begin{array}{c}-.3172 \\
(2.873)\end{array}$ & $\begin{array}{r}-.1451 \\
(1.832)\end{array}$ & $\begin{array}{r}-.2113 \\
(3.651)\end{array}$ & $\begin{array}{r}-.3030 \\
(8.712)\end{array}$ \\
\hline M.D. & 0 & 0 & 0 & $\begin{array}{r}.1562 \\
(.9805)\end{array}$ & $\begin{array}{r}.6379 \\
(4.282)\end{array}$ & $\begin{array}{r}.5951 \\
(5.849)\end{array}$ \\
\hline Lawyer & $\begin{array}{r}.1799 \\
(.3513)\end{array}$ & $\begin{array}{l}.05596 \\
(.1533)\end{array}$ & $\begin{array}{r}1.133 \\
(2.328)\end{array}$ & $\begin{array}{r}-.2523 \\
(2.463)\end{array}$ & $\begin{array}{c}-.1469 \\
(1.665)\end{array}$ & $\begin{array}{r}.2253 \\
(4.378)\end{array}$ \\
\hline$R^{2}$ & .01169 & .07080 & .07462 & .07785 & .18832 & .30365 \\
\hline Observations & 2436 & 2074 & 2241 & 568 & 485 & 856 \\
\hline $\begin{array}{l}\mathrm{R}^{2} \text { prior to } \\
\text { occupations }\end{array}$ & .00586 & .05837 & .05877 & .06066 & .12532 & .17303 \\
\hline
\end{tabular}

\section{a} Education and occupations in 1955 used in regression. 
these revisions in the estimates, the results are virtually identical with the previous table. Education is significant throughout the period, as is IQ generally. However, college and graduate school quality is not significant for either group in their first year in the labor force, but it becomes statistically significant by 1955 for both groups and becomes even more significant with a larger coefficient in the 1969 earnings function. It is also interesting to note that about 6 per cent of the variance for those who had sixteen or fewer years of education can be explained in each of the years. However, for those with some graduate education the $\mathrm{R}^{2}$ rises from roughly .06 in the initial year of earnings to .12 in 1955 and to .19 in 1969. It appears that the variables in our earnings function become progressively more important determinants of earnings over time for those with the highest levels of education, whereas the factors not included play a larger and constant role over time for those with sixteen or fewer years of schooling. 47

\section{7} ual Christopher Jencks attributes the large amount of variance in individual earnings not explainable by traditional variables to the fact that luck and random forces predominate and are the main influences on individual income differences. Certainly there are random elements involved in lifetime earnings streams. We would like to stress the things we do know about income determination rather than the things we don't know. However, it does appear from these regressions at different points in the life cycle that random elements are a weaker force for those people who attend graduate school, and this luck or randomness seems to decline over time for those who have attended graduate school. On the other hand, the unexplainable portion of income differences among individuals is the same for those with sixteen or fewer and those with more than sixteen years of schooling when they initially enter the labor force. However, the role of these random forces does not seem to decline over time for those who do not go to graduate school, contrary to what happens for those who do go on. 
The strong results we get when we attempt to explain differences in individual incomes at different points in the life cycle lead us to see whether a similar model explains the growth rate of income for individuals between the years 1955 and 1969. It appears once again in Table 14 that we can only explain a small amount of the difference in growth rates among individuals for those who had sixteen or fewer years of education. Moreover, none of the variables in the model that were significant in explaining income differences in any one year had a $t$-value greater than 2 when used to explain the growth rate of income between the two dates specified. For those with more than sixteen years of schooling the $\mathrm{R}^{2}$ is almost .15, more than four times greater than the $\mathrm{R}^{2}$ for the undergraduates. It appears that differences in years of education, IQ, and quality of at least undergraduate school have statistically significant effects in explaining the growth rate of income. These results are even more difficult to interpret because of the small sample sizes. The samples are small because the income growth figure was calculated only for those who had incomes in both 1955 and 1969.

VI. How Quality Makes Its Impact

Earlier in the paper we noted that institutional variables relating to student quality and some relating to faculty salaries were separate and significant determinants of college quality. Since then, we have reverted to using the Gourman ratings as our measure of quality. These are highly correlated with the S.A.T. and salary data but are available for a larger number of institutions. This enables our sample sizes 
TABLE 14

Regressions to Explain Rate of Change of Income Between 1955 and 1969

\begin{tabular}{|c|c|c|c|}
\hline & Education $\leq 17$ & Education $\geq 17$ & $\begin{array}{l}\text { Total } \\
\text { Sample }\end{array}$ \\
\hline Constant & $\begin{array}{l}-214.9 \\
(.4086)\end{array}$ & $\begin{array}{r}-1.418 \\
(-1.765)\end{array}$ & $\begin{array}{l}-258.6 \\
(.6198)\end{array}$ \\
\hline Years of education & $\begin{array}{r}53.65 \\
(1.732)\end{array}$ & $\begin{array}{r}85.35 \\
(2.432)\end{array}$ & $\begin{array}{r}45.08 \\
(1.937)\end{array}$ \\
\hline Experience & $\begin{array}{r}30.46 \\
(1.063)\end{array}$ & $\begin{array}{r}16.84 \\
(.3809)\end{array}$ & $\begin{array}{r}35.58 \\
(1.527)\end{array}$ \\
\hline Experience ${ }^{2}$ & $\begin{array}{l}-.7753 \\
(1.077)\end{array}$ & $(.2352$ & $\begin{array}{r}-.8038 \\
(1.355)\end{array}$ \\
\hline I.Q. & $\begin{array}{r}39.31 \\
(1.996)\end{array}$ & $\begin{array}{r}55.94 \\
(3.035)\end{array}$ & $\begin{array}{r}45.68 \\
(3.098)\end{array}$ \\
\hline Undergraduate quality & $\begin{array}{r}.6678 \\
(1.882)\end{array}$ & $\begin{array}{r}1.020 \\
(2.940)\end{array}$ & $\begin{array}{r}.8149 \\
(3.064)\end{array}$ \\
\hline Graduate quality & & $\begin{array}{r}.4648 \\
(1.454)\end{array}$ & $\begin{array}{r}-.02434 \\
(.1548)\end{array}$ \\
\hline Pilot & $\begin{array}{l}-103.5 \\
(.2448)\end{array}$ & 0 & $\begin{array}{r}-109.1 \\
(.2826)\end{array}$ \\
\hline Teacher & $\begin{array}{l}-317.0 \\
(1.097)\end{array}$ & $\begin{array}{l}-282.4 \\
(3.084)\end{array}$ & $\begin{array}{l}-300.1 \\
(2.703)\end{array}$ \\
\hline M.D. & 0 & $\begin{array}{l}-912.3 \\
(1.631)\end{array}$ & $\begin{array}{l}-880.2 \\
(1.139)\end{array}$ \\
\hline Lawyer & 0 & $\begin{array}{l}-540.7 \\
(2.819)\end{array}$ & $\begin{array}{l}-533.9 \\
(2.112)\end{array}$ \\
\hline$R^{2}$ & .03393 & .20160 & .05507 \\
\hline Observations & 648 & 260 & 908 \\
\hline $\mathrm{R}^{2}$ prior to occupations & .03202 & .14897 & .04265 \\
\hline
\end{tabular}


to be larger, a fact that is particularly important when we start subdividing the samples. This section will continue to employ the Gourman ratings for these reasons.

The assumption so far has been that quality has its impact as a continuous variable. The assumption is that not only do good schools mean more in terms of lifetime earnings than do bad schools, but also that schools better by a certain number of points are worth a certain amount more in terms of lifetime income. That is, there is some transformation coefficient that can tell us how much more in terms of, say, dollars in 1969 it was worth to our respondents to have attended a school better than another by a certain number of quality points. It is now time to ask whether quality does function as a continuous variable or whether the significance of quality when used as a continuous variable resulted merely because gross differences in schools are important but fine gradations of differences are not.

To this end, we separated our sample into those with sixteen or fewer years and those with seventeen or more years, and within each of those two subgroups we looked at individuals who had attended schools in each of four quality quartile rankings. These results appear as Tables 15 and 16. For those without any graduate training, the coefficients on undergraduate quality within each quality quartile was virtually always insignificant. In several quality quartiles the coefficient on quality was negative also. Variations on quality within a quartile appear to be significant only for those who attended schools in the top quality quartile.*

"The significant quality variable was the expenditure per student - a different criteria than the one used to divide individuals into "quality
quartiles." 
Earnings Functions For Undergraduates

By

Institutional Quality Quartiles

Undergraduates - Gourman Overall

Low

ist quartile

Gourman

$2.194 \quad 1.890$

(5.739)

(6.385)

$.04699 \quad .04841$

(2.833)

(2.918)

$.007229 \quad .006823$

Experience

(.4083) (.3851)

2nd Quartile

3rd Quartile

Ed. Yrs.

Gourman

Library Gourman

Constant

$2.240 \quad 1.617$

2.180

(4.526) (5.238)

(3.821)

$.05436 \quad .05468$

.06353

(3.273)

(3.287)

(3.569) $.03154 \quad .02997$

.01728

(1.491)

(1.416)

(.8751)
High

4th Quartile

$.0001799-.0001729$

Library Gourman

Library

1.615

.8881

.9965

(5.144)

(1.655)

(2.120)

.06216

.08777

.09093

(3.495)

(3.077)

(3.238)

Experience 2

$$
\text { (.4157) (.3991) }
$$

.01742

.02237

.02657

IQ

$\begin{array}{ll}.01979 & .01865 \\ (1.646) & (1.541)\end{array}$

(.8807)

(.9765)

(1.171)

$.5824 \quad .5695$

$-.0007062-.0006604$

$-.0002044-.0002109$

$-.000$

3688

$-.0004744$ 
Earnings Functions For Graduates By

Institutional Quality Quartiles

Graduate Gourman overall

Low

lst Quartile

2nd quartile

High

3rd quartile

4th Quartile

\begin{tabular}{|c|c|c|c|c|c|c|c|c|}
\hline \multirow{3}{*}{ Constant } & Gourman & Library & Gourman & Library & Gourman & Library & Gourman & Library \\
\hline & .4557 & .7612 & .8856 & .8828 & .6624 & 1.946 & .07469 & 1.433 \\
\hline & $(.6379)$ & $(1.251)$ & $(1.141)$ & $(1.800)$ & $(.6013)$ & $(1.980)$ & $(.05236)$ & $(1.302)$ \\
\hline \multirow[t]{2}{*}{ Ed. Yrs. } & .09634 & .09322 & .08904 & .08835 & .04772 & .04180 & .1187 & .1017 \\
\hline & $(3.422)$ & $(3.313)$ & $(4.282)$ & $(4.248)$ & $(1.368)$ & $(1.196)$ & $(2.480)$ & $(2.174)$ \\
\hline
\end{tabular}

Experience

$.02658 \quad .02557$

.02569

.02730

$-.05828 \quad-.03869$

$-.08445$

$-.09060$

$(.7640)$

(.7344)

(.9165)

(.9708)

$(.9628) \quad(.6426)$
$(.64)$

(1.208)

(1.300)

Experience 2

$\begin{array}{cccc}-.0004527 & -.0004371 & -.0004032 & -.0004549 \\ (.4685) & (.4516) & (.5344) & (.6013)\end{array}$

.001495

.001026

(1.015)

(.7007)

.003259

.003324

IQ

$\begin{array}{ll}.05109 & .05173 \\ (3.616) & (3.646)\end{array}$

$.02279 \quad .02527$

.01452

.02011

(1.715)

(1.752)

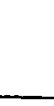

Pilot

00

(1.673)

(1.850)

(.8364)

(1.164)

.03516

.03110

$0 \quad .7285 \quad .7274$

(1.905) (1.902)

0

0

0

(1.693)

(1.498)

Teacher

$$
-.2618
$$

$-.2746$

$-.2971-.2999$

$(4.353) \quad(4.611)$

$\begin{array}{cc}-.2971 & -.2999 \\ (5.553) & (5.631)\end{array}$

$\begin{array}{ll}-.2362 & -.2648 \\ (2.720) & (3.094)\end{array}$

$.6243 \quad .6209$

.5769

.5482

$(2.460) \quad(2.338)$

(4.094)

(4. 123)

(4. 391)

.2556

.3411.

(3. 366)

.2690

.09133

(3.534)

$(.7426)$

.06066

(.4909)

(1.

$\begin{array}{cc}.05529 & .2275 \\ (.1142) & (.4728)\end{array}$

UG Quality

\begin{tabular}{ccccccccc}
.0004963 & .00002767 & .0002823 & .0000006242 & .0006205 & .0001344 & .0005796 & .00005233 \\
$(1.390)$ & $(.3432)$ & $(1.139)$ & $(.01067)$ & $(1.543)$ & $(1.405)$ & $(1.922)$ & $(.8004)$ \\
\hline-.00003353 & -.00007394 & -.0002209 & .00002716 & .002972 & .0003710 & .001265 & .0001048 \\
$(.04048)$ & $(.6795)$ & $(.1899)$ & $(.3415)$ & $(2.869)$ & $(2.677)$ & $(1.184)$ & $(1.632)$ \\
\hline
\end{tabular}

\begin{tabular}{ccccccccc}
.0004963 & .00002767 & .0002823 & .0000006242 & .0006205 & .0001344 & .0005796 & .00005233 \\
$(1.390)$ & $(.3432)$ & $(1.139)$ & $(.01067)$ & $(1.543)$ & $(1.405)$ & $(1.922)$ & $(.8004)$ \\
\hline-.00003353 & -.00007394 & -.0002209 & .00002716 & .002972 & .0003710 & .001265 & .0001048 \\
$(.04048)$ & $(.6795)$ & $(.1899)$ & $(.3415)$ & $(2.869)$ & $(2.677)$ & $(1.184)$ & $(1.632)$ \\
\hline
\end{tabular}

.0006205

$\begin{array}{cc}(.1142) & (.4728) \\ -.3605 & -.3515 \\ (3.181) & (3.074)\end{array}$

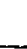

Gr

Grad Qualit

$\sqrt{2}$

.44645

.44247

.32023

.31757

.20719

.20114

.23427

.23328

2.12

321

178

145

$\mathrm{R}^{2}$ step8

.44111

.31730 
For the undergraduates it should be noted that the effect of years attended rose continually from the lowest to the highest quartile. This is a sign of a positive interaction between years attended and college quality in affecting lifetime earnings. More about this will come later. It also appears that the impact of IQ rises continually from the lowest to the second-highest quality quartile, but IQ becomes statistically insignificant for those attending schools ranked in the top-quality quartile.

The results for those students who had at least some graduate training are quite similar. For students attending schools in the lower two quality quartiles, the quality of their undergraduate or graduate school attended was insignificant and at times negative. Surprisingly, those who attended graduate schools ranked in the third (next to highest) quartile revealed significant effects of quality of graduate schools on 1969 earnings, and those in the fourth quartile, or the highest quality schools, revealed a somewhat weaker effect than was revealed in the third quartile, but one nearer to significance compared to those in the lower half of the quality distribution. It also appears that the effect of years attended on income falls between the lowest and next-to-highest quality quartile but is highest and significant in the top-quality quartile also. Differential impacts of IQ across quality quartiles also appears U-shaped, with IQ being most significant in the lowest quartile, declining through the third quartile, and being relatively high again in the top-quality quartile. 
The results for both undergraduate and graduate students appear to imply that although large differences in college quality matter, once we have subdivided individuals according to gross differences in the types of college attended, small differences within these categories don't much matter. As a test, we developed a set of duminy variables that for any individual equaled zero in three cases and one for the variable representing that quality quartile in which the school he attended fell. We then estimated an earnings function for all those with sixteen or fewer years and then for all those with more than sixteen years, inserting dumy variables representing three of the four quality quartiles. This estimate appears as Table 17. It appears that to be in the top-quality quartile of schools implies a higher income, and to be in the bottom quartile implies a smaller income than average, but the two middle quartiles basically yield average coefficients. We then divided the quality distribution of schools into eighths rather than quarters and inserted seven of the eight dumies as independent variables in the earnings function. This is presented in Table 18. Once again it appeared that to be in the top two-eighths of the quality distribution if you had only attended as an undergraduate, or to be in the top three-eighths of the quality distribution if you had some graduate training, would result in a statistically significant, higher-than-average income. Moreover, it also appeared that those who attended schools of the lowest quality had lower-than-average incomes. In conclusion, it appears that it matters whether you are attending a 
TABLE 17

Earnings Functions

with

Quality Quartiles

In

Single Regressions By Attainment

Gourman

$\begin{array}{cc}\leqslant 16 \text { Years } & \geqslant 16 \text { Years } \\ \text { of Education } & \text { of Education }\end{array}$

\begin{tabular}{|c|c|c|}
\hline Constant & $\begin{array}{c}1.690 \\
(10.58) \\
\end{array}$ & $\begin{array}{c}1.345 \\
(3.991) \\
\end{array}$ \\
\hline Ed, Yrs. & $\begin{array}{l}.05901 \\
(6.373) \\
\end{array}$ & $\begin{array}{l}.07653 \\
(5.324) \\
\end{array}$ \\
\hline Experience & $\begin{array}{l}.01776 \\
(1.790) \\
\end{array}$ & $\begin{array}{l}.008451 \\
(.4229) \\
\end{array}$ \\
\hline Experience $^{2}$ & $\begin{array}{c}-.0003273 \\
(1.335)\end{array}$ & $\begin{array}{r}.00008836 \\
(.1662)\end{array}$ \\
\hline IQ & $\begin{array}{l}.02433 \\
(4.045) \\
\end{array}$ & $\begin{array}{l}.03534 \\
(4.595) \\
\end{array}$ \\
\hline Pilot & $\begin{array}{c}.4940 \\
(4.928) \\
\end{array}$ & $\begin{array}{c}.4707 \\
(1.618) \\
\end{array}$ \\
\hline Teacher & $\begin{array}{r}-.3190 \\
(2.887) \\
\end{array}$ & $\begin{array}{r}-.3079 \\
(8.861) \\
\end{array}$ \\
\hline$M D$ & 0 & $\begin{array}{r}.6202 \\
(6.067) \\
\end{array}$ \\
\hline Lawyer & $\begin{array}{l}1.203 \\
(2.471) \\
\end{array}$ & $\begin{array}{r}.2431 \\
(4.707) \\
\end{array}$ \\
\hline $\begin{array}{l}\text { Gourman } \\
\text { lst Quartile }\end{array}$ & $\begin{array}{r}-.06193 \\
(2.219) \\
\end{array}$ & $\begin{array}{r}-.1531 \\
(3.630) \\
\end{array}$ \\
\hline $\begin{array}{l}\text { Gourman } \\
\text { 2nd Quartile }\end{array}$ & $\begin{array}{r}-.001570 \\
(.05707) \\
\end{array}$ & $\begin{array}{r}-.05969 \\
(1.551) \\
\end{array}$ \\
\hline $\begin{array}{l}\text { Gourman } \\
\quad \text { 4rd Quartile }\end{array}$ & $\begin{array}{r}.1353 \\
(4.262) \\
\end{array}$ & $\begin{array}{r}.1190 \\
(2.584) \\
\end{array}$ \\
\hline $\mathrm{R}^{2}$ & .07576 & .30083 \\
\hline Observations & 2241 & 856 \\
\hline
\end{tabular}


$-59-$

I'ARLF 18

Earnings Functicrs

Wi.th

Quality fighths

In

Golinar

Single Regressions By Attainment

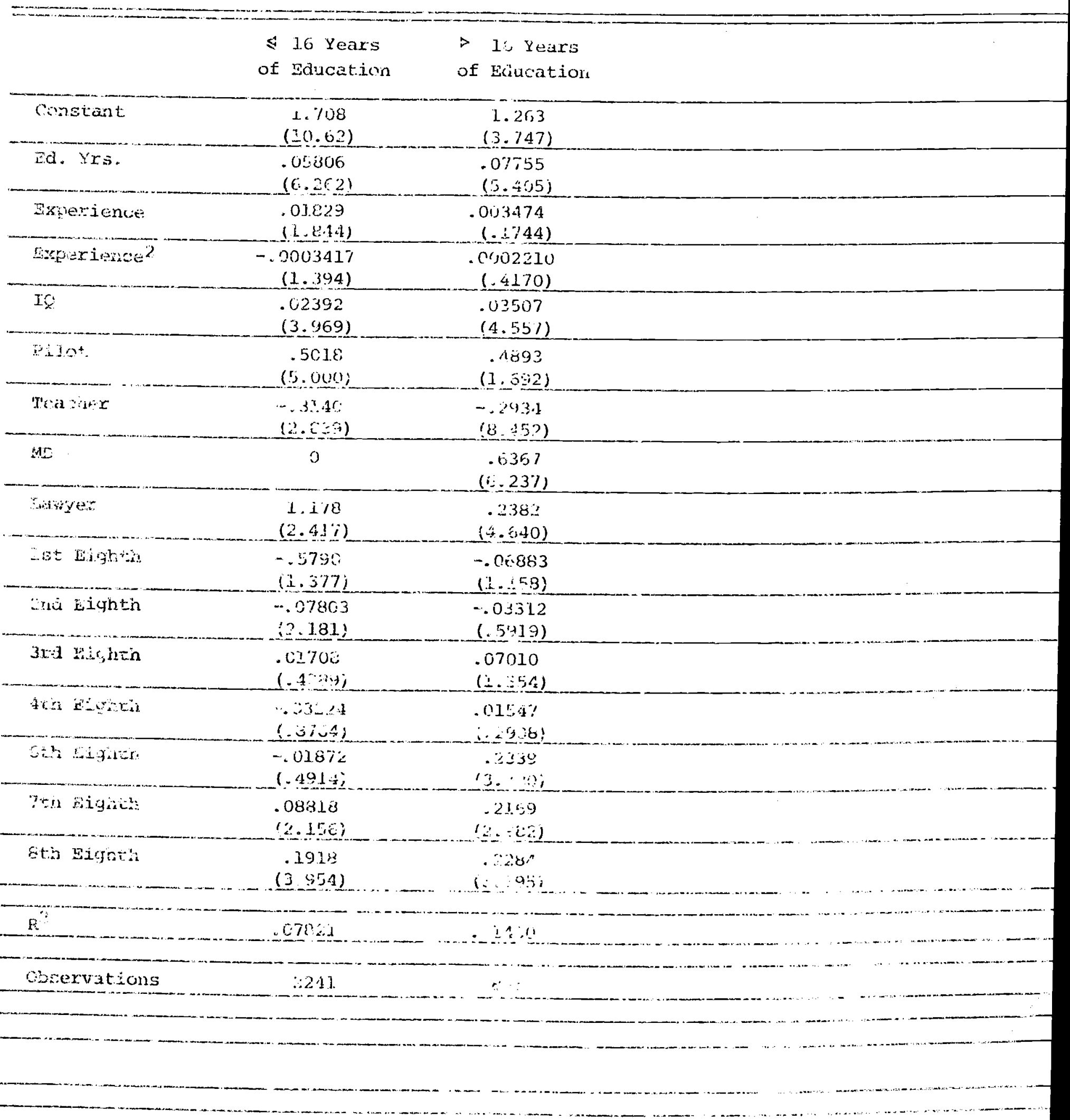


good or a bad school. It is better to go to a good school. However, within any set of, say, good schools, it does not matter much about small differences in quality.

Another way to look at same type of question is to see the significance of quality, as measured by the Gourman ratings, for schools within a particular categorization of institutions. The categorization we select is that of the Carnegie Commission on Higher Education. They place institutions into categories such as "leading" and "other research" institutions (codes 10 and 20). "large" and "small doctoral-granting" institutions (codes 30 and 40), four-year colleges with "large" and "small program selections" (codes 50 and 60), and "liberal arts" colleges, "highly selective," and "others" (codes 70 and 80 ). We have combined certain of these categories and looked at the effects of courman quality on earnings of individuals who attended particular categories of institutions.

Table 19 reveals that for those without graduate training, differences in expenditures per student, as well as differences in courman ratings, were significant factors in income determination, even when students were initially categorized into those who attended one of the four university types and those who attended one of the four types of college. However, quality differences seem to matter more (according to the $t$-test) for those attending universities than it did for those attending colleges. For those who had some graduate training, it appeared that differences in Gourman rating or expenditures per student were significant for those who attended graduate school at leading research or doctoral-granting institutions (codes 10 through 40). Apparently, 
TABLE 19

Earnings Functions For Groups of Individuals Sorted Into

Carnegie Type of Institutions

Carnegie Code Regressions

Education $4 \quad 17$

Carnegie Codes

$10-40 \quad 50-80$
Gourman

Education $\geqslant 17$
Li.brary

Carnegie Codes 10-40 50-80
Gourman

Carnegie codes $10-40 \quad 50-80$
Iibrary

Carnegie codes $10-40 \quad 50-80$

$\begin{array}{lcccc}\text { Constant } & \begin{array}{c}1.196 \\ (5.766)\end{array} & \begin{array}{c}1.481 \\ (4.594)\end{array} & \begin{array}{c}1.343 \\ (6.711)\end{array} & \begin{array}{c}1.719 \\ (6.009)\end{array} \\ \text { Ed. Yrs. } & \begin{array}{l}.06545 \\ (5.672)\end{array} & \begin{array}{l}.05060 \\ (3.077)\end{array} & \begin{array}{c}.06725 \\ (5.845)\end{array} & \begin{array}{l}.05085 \\ (3.092)\end{array} \\ \text { Experience } & \begin{array}{c}.02079 \\ (1.746)\end{array} & \begin{array}{c}.01616 \\ (.8331)\end{array} & \begin{array}{l}.02232 \\ (1.872)\end{array} & \begin{array}{l}.01535 \\ (.7902)\end{array} \\ \text { Experience }^{2} & \begin{array}{c}-.0003592 \\ (1.215)\end{array} & \begin{array}{c}.0003577 \\ (.7580)\end{array} & \begin{array}{c}.0003962 \\ (1.339)\end{array} & \begin{array}{c}.0003388 \\ (.7167)\end{array} \\ \text { IQ } & .02216 & .02519 & .02311 & .02589 \\ & (3.095) & (2.132) & (3.243) & (2.201)\end{array}$

UG Quality $.0007053 .0009192 \quad .0001622 \quad .0001832$ $\begin{array}{llll}(5.027) & (2.145) & (5.178) & (2.081)\end{array}$

\begin{tabular}{cccc}
$\begin{array}{c}.4733 \\
(1.211 .)\end{array}$ & $\begin{array}{c}1.418 \\
(1.664)\end{array}$ & $\begin{array}{c}.9152 \\
(2.401)\end{array}$ & $\begin{array}{c}1.656 \\
(2.140)\end{array}$ \\
$\begin{array}{c}.08649 \\
(5.531)\end{array}$ & $\begin{array}{c}.07277 \\
(1.876)\end{array}$ & $\begin{array}{c}.08295 \\
(5.280)\end{array}$ & $\begin{array}{c}.06920 \\
(1.799)\end{array}$ \\
$\begin{array}{c}.008734 \\
(.3903)\end{array}$ & $\begin{array}{c}.02150 \\
(.4554)\end{array}$ & $\begin{array}{c}.01274 \\
(.5665)\end{array}$ & $\begin{array}{c}.02070 \\
(.4374)\end{array}$ \\
.0001418 & .0008482 & .00001947 & .0008135 \\
$(.2410)$ & $(.6213)$ & $(.03293)$ & $(.5948)$ \\
.02831 & .03608 & .03184 & .03907 \\
$(3.257)$ & $(1.945)$ & $(3.661)$ & $(2.091)$ \\
\hline 0004802 & .0002079 & .00004638 & -.00003344 \\
$(2.989)$ & $(.5298)$ & $(1.252)$ & $(.3633)$
\end{tabular}

0
$.0007669 .00005739 .0001552 \quad-.00004860$ $\begin{array}{llll}(4.991) & (.07230) & (5.027) & (.2958)\end{array}$
Grad Quality

0

0

0

.4045

(1.373)

0

.4898

$\begin{array}{llll}(3.814) & (3.026) & (3.828) & (3.034)\end{array}$

$-.3127$

$(8.034) \quad(2.829) \quad(8.150) \quad(2.991)$

$-.2185$

.4986

(1.684)

0

MD

(.9039)

$(.9540)$

(2.863)

.6245

.6718

.6135

.7066

$\begin{array}{llll}(5.191) & (3.463) & (5.074) & (3.409)\end{array}$

Lawyer

\begin{tabular}{cccc}
1.258 & 0 & $\begin{array}{c}1.143 \\
(2.365)\end{array}$ & 0 \\
\hline
\end{tabular}

(2.365)
.1921

(3.373)
.3745

(2.948)
.1966

(3.441)
.3861

$(3.040)$
$\mathrm{R}^{2}$

Observations

.07370

.06642

.0746

.06602

.29365

.28471

.41435

1563

644

1563

644

719

134

719

134 
134 people who went to graduate school went to institutions with codes between 50 and 80. Presumably, these were people who got only a master's degree, and for them differences in Gourman or expenditures were not significant factors in the earnings function.

It should be noted that when individuals were further separated into finer classifications, as determined by Carnegie (that is, research universities, doctoral-granting universities, four-year colleges, and liberal arts colleges), it appeared that quality became progressively less important as the Carnegie codes increased for undergraduates as well as for graduates. 48 However, it should be noted that for both those with less than seventeen and with seventeen or more years of schooling, differences in quality were most significant for those at research institutions and for those at doctoral-granting institutions. When the average S.A.T. scores of entering freshmen and average faculty salary variables were used as measures of quality within Carnegie classes, they were significant primarily at the leading research universities and doctoral institutions as well. These results are not presented.

We have established that small differences in quality of institutions attended do not explain income differences among individuals categorized according to the quartile rating of the university they

48 Carnegie Commission. Dissent and Disruption. A Report of the Carnegie Comission. Berkeley, California: The Carnegie Commission on Higher Education, 1971. (Appendix C.), describes the Carnegie classifications in more detail. 
attended. However, quality does explain income differences among people categorized according to the type of institution attended. This implies that the variation in quality of institutions categorized into combined Carnegie classifications is greater than is the variance in quality among institutions classified by quality quartiles. When we look at smaller combinations of Carnegie classes or at individual Carnegie classes, it appears that college quality is not as important an explanatory variable in explaining income differences of people attending a particular type of college.

VII. The Trade-Off Between Quantity and Quality of Education

So far we have determined that quality coefficients increase in size and significance with years of school attended (the coefficients are higher for those with graduate school training compared to those with only undergraduate training). Moreover, the years's coefficient rises as the quality of colleges attended by undergraduates rises (the evidence is from comparing quality quartiles into which those attending sixteen or fewer years have been divided). The year's coefficient is U-shaped when comparing graduate quality quartiles for those with geventeen or more years. That is, the year's coefficient is high in the lowest quartile, falls in the second quality quartile, but continues to rise, with the highest quallty quartile denonstrating the largest year's coefficient. These results imply that the payoff to going to a good school is higher if you go to school for more years. 
However, this does not answer the question of whether we can say that two years at Harvard are better than more years at a lower quality institution. Rather, these results imply that more years at Harvard are worth more than fewer years at Harvard.

Table 20 divides those people who attended school for seventeen or more years according to the quality of their undergraduate institution. The purpose here is to see whether the quality of a graduate school and the impact of more years attended varied according to the undergraduate institution attended. It does appear that the year's coefficient is significantly greater for those who attended undergraduate schools ranked in the lowest two quality quartiles. The year's coefficient is not even statistically significant according to the t-test for those in the top half of the undergraduate quality distribution. Hence, it appears that extra years are more important for those who went to a bad undergraduate school than for those who went to a good one. Moreover, it appears that the payoff to quality of graduate school rises continuously as we move from individuals who attended the lowest quality undergraduate schools to those who attended the next-to-highest quality. However, for those who attended the highest quality undergraduate schools the payoff to quality of graduate school is almost as low as that in any quartile. It appears that there is a complementarity between the quality of undergraduate school and the quality of graduate school. Once again even though you can partially compensate for going to a bad school by attending for more years, the payoff to going to a good school is higher for those whose earlier experience was also at a good school. 
Earnings Functions For Those with Graduate Training Sorted According To

Quality Quartile o. Undergraduate Institutions

Graduates

Undergraduate Gourman

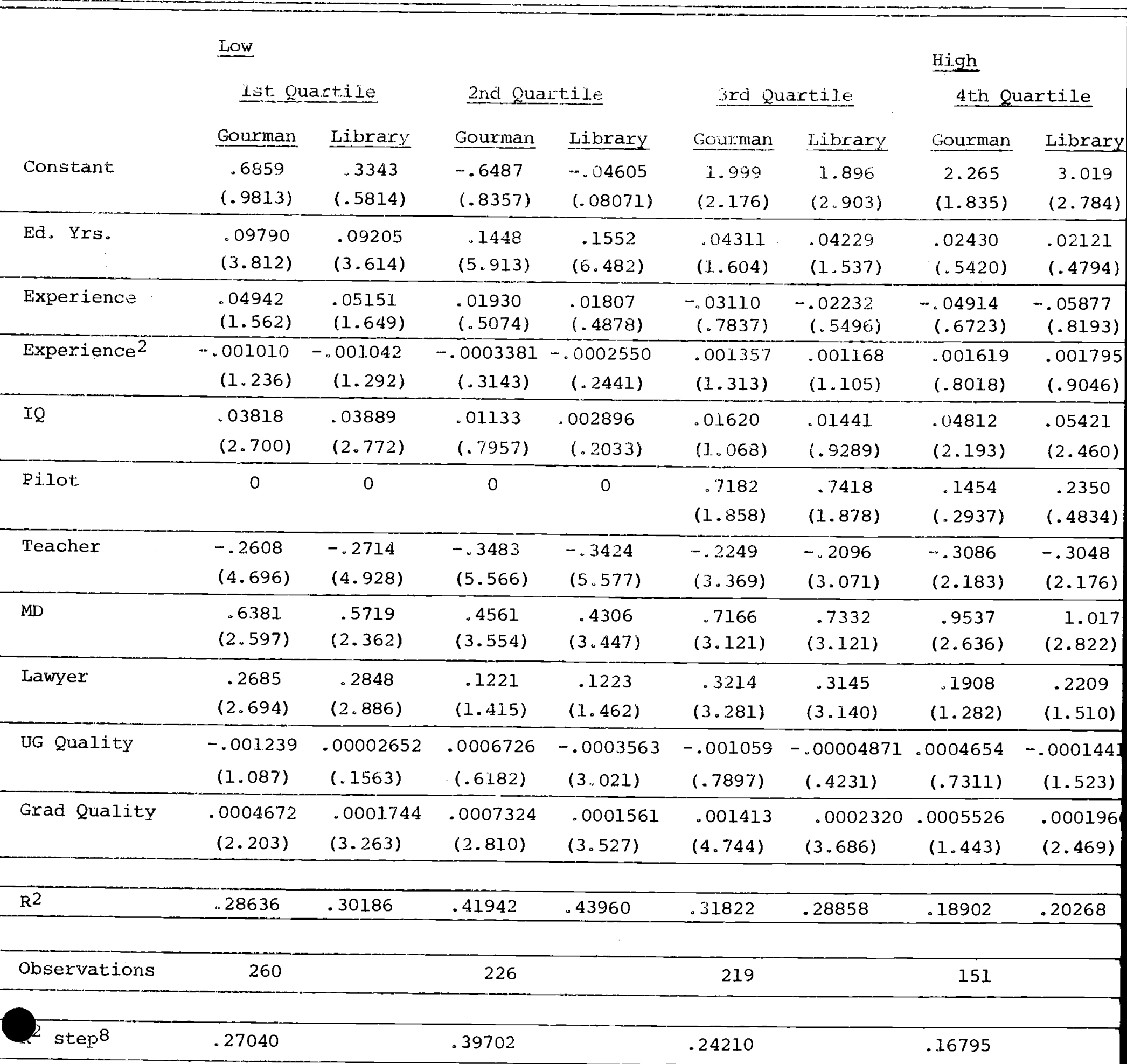


VIII. The Differences in Effects of guality in Public and in Private Institutions

There are a number of reasons for looking at the effects of quality of institutions attended broken down according to those who attended private institutions and those who attended public ones. In the first place, the question might be raised of whether or not a private institution can allocate its expenditures more effectively and, hence, make a given expenditure per full-time equivalent student more effective in terms of lifetime benefits for the student. Here I refer to the multitude of constituencies that, by necessity, are served by a public institution. If one looks at athletic programs, for example, it seems that in general it is the public schools that engage in these most extensively. It might be that a public institution has a greater diversity of objectives than does private institutions, regardless of its quality. This does appear to be the case. Tables 21 and 22 show that basic expenditures per student and expenditures on faculty, research, and library facilities both affect those with sixteen or fewer and seventeen or more years of schooling more when they attend a private school than when they attend a public school. This implies to me that any level of expenditures will be directed towards activities which are more beneficial in terms of future lifetime earnings by a private school.

Moreover, it appears that the returns to quality, as measured by the Gourman Index, are higher for those attending private than for those attending public schools. The Gourman Index is a composite of a number of characteristics, including size of the institution. Hence, it appears

*For example, in Playboy Magazine's predictions of the 1973 top twenty college football teams in the nation, they anticipate that 17 of the top twenty teams will be from public institutions. See playboy, September, 1973. p. 172 . 
Earnings Functions For Undergraduates Sorted According

To Whether They Attended

Public or Private Institutions

Public and Private Regressions

Education 417

\begin{tabular}{|c|c|c|c|c|c|c|}
\hline & Gou & rman & Basic Exp & enditures & $\underline{\text { Lib }}$ & rary \\
\hline & Public & Private & Public & Private & Public & Private \\
\hline Constant & $\begin{array}{r}1.528 \\
(7.268) \\
\end{array}$ & $\begin{array}{c}1.327 \\
(5.122) \\
\end{array}$ & $\begin{array}{c}1.561 \\
(7.638)\end{array}$ & $\begin{array}{c}1.478 \\
(5.819)\end{array}$ & $\begin{array}{c}1.582 \\
(7.750)\end{array}$ & $\begin{array}{r}1.488 \\
(5.858\end{array}$ \\
\hline Ed. Yrs. & $\begin{array}{l}.05223 \\
(4.341) \\
\end{array}$ & $\begin{array}{l}.06805 \\
(4.693) \\
\end{array}$ & $\begin{array}{l}.05247 \\
(4.380) \\
\end{array}$ & $\begin{array}{l}.06946 \\
(4.788) \\
\end{array}$ & $\begin{array}{l}.05299 \\
(4.419) \\
\end{array}$ & $\begin{array}{l}.06914 \\
(4.761) \\
\end{array}$ \\
\hline Experience & $\begin{array}{l}.02680 \\
(1.970) \\
\end{array}$ & $\begin{array}{l}.01331 \\
(.9088) \\
\end{array}$ & $\begin{array}{l}.02623 \\
(1.928)\end{array}$ & $\begin{array}{l}.01391 \\
(.9480)\end{array}$ & $\begin{array}{l}.02648 \\
(1.945) \\
\end{array}$ & $\begin{array}{l}.01407 \\
(.9579) \\
\end{array}$ \\
\hline Experience 2 & $\begin{array}{c}-.0005256 \\
(1.537) \\
\end{array}$ & $\begin{array}{c}-.0002693 \\
(.7583)\end{array}$ & $\begin{array}{c}-.0005065 \\
(1.481)\end{array}$ & $\begin{array}{c}-.0002865 \\
(.8050)\end{array}$ & $\begin{array}{c}-.0005146 \\
(1.504)\end{array}$ & $\begin{array}{r}-.000289 \\
(.8132) \\
\end{array}$ \\
\hline IQ & $\begin{array}{l}.02146 \\
(2.784) \\
\end{array}$ & $\begin{array}{c}.02957 \\
(3.112) \\
\end{array}$ & $\begin{array}{l}.02176 \\
(2.839) \\
\end{array}$ & $\begin{array}{l}.02880 \\
(3.002) \\
\end{array}$ & $\begin{array}{l}.02230 \\
(2.910) \\
\end{array}$ & $\begin{array}{l}.03001 \\
(3.142 \\
\end{array}$ \\
\hline UG Quality & $\begin{array}{r}.0002922 \\
(1.692) \\
\end{array}$ & $\begin{array}{r}.0007123 \\
(5.065) \\
\end{array}$ & $\begin{array}{c}.00008011 \\
(2.108)\end{array}$ & $\begin{array}{c}.00009639 \\
(4.783) \\
\end{array}$ & $\begin{array}{c}.00008378 \\
(1.564)\end{array}$ & $\begin{array}{r}.0001503 \\
(4.640) \\
\end{array}$ \\
\hline Grad Quality & 0 & 0 & 0 & 0 & 0 & 0 \\
\hline Pilot & $\begin{array}{r}.5649 \\
(3.589) \\
\end{array}$ & $\begin{array}{c}.4291 \\
(3.244) \\
\end{array}$ & $\begin{array}{r}.5708 \\
(3.627) \\
\end{array}$ & $\begin{array}{c}.4323 \\
(3.262)\end{array}$ & $\begin{array}{c}.5645 \\
(3.586) \\
\end{array}$ & $\begin{array}{r}.4358 \\
(3.286) \\
\end{array}$ \\
\hline Teacher & $\begin{array}{l}-.3426 \\
(2.671) \\
\end{array}$ & $\begin{array}{l}-.2203 \\
(1.055) \\
\end{array}$ & $\begin{array}{r}-.3476 \\
(2.719) \\
\end{array}$ & $\begin{array}{r}-.2167 \\
(1.036) \\
\end{array}$ & $\begin{array}{l}-.3531 \\
(2.761) \\
\end{array}$ & $\begin{array}{r}-.2033 \\
(.9717) \\
\end{array}$ \\
\hline MD & 0 & 0 & 0 & 0 & 0 & 0 \\
\hline Lawyer & 0 & $\begin{array}{r}1.162 \\
(2.290) \\
\end{array}$ & 0 & $\begin{array}{c}1.112 \\
(2.189)\end{array}$ & 0 & $\begin{array}{c}1.072 \\
(2.109) \\
\end{array}$ \\
\hline $\mathrm{R}^{2}$ & .05779 & .09612 & .05898 & .09359 & .05748 & .09236 \\
\hline Observations & 1260 & 980 & 1260 & 980 & 1260 & 980 \\
\hline $\begin{array}{l}\mathrm{R}^{2} \text { prior to } \\
\text { Rccupations }\end{array}$ & .04262 & .08043 & .04343 & .07819 & .04197 & .07723 \\
\hline
\end{tabular}


Earnings Functions For Those with Graduate Training

Sorted According to whether

They Attended Public or Private Institutions

Public and Private Regressions

Education $\geqslant 17$

Gourman

Public Private

Constant

Constant

Ers.

.3482

1.041

(.8449)

(1.871)

Ed. Yrs.

$.1013 \quad .06528$

(5.745)

(2.904)

Experience

$.01570-.009517$

(.7104)

(.2634)

Experience $^{2}$

$-.0002461 \quad .0008187$

(.4186)

(.8499)

IQ

$.02318 \quad .03253$

(2.245) (2.785)

UG Quality

$.0003751 \quad .0004490$

(1.770)

(2.156)

$.0005211 \quad .0007003$

(2.454)

(3.904)

.5144

0

(1.990)

0

Basic Expenditures

Public Private

$$
.5852
$$

1.503

(1.435)

(2.790)

$.1023 \quad .05950$

(5.751) (2.658)

.01889

$-.006314$

(.8481) (.1738)

$-.0003395 \quad .0006936$

(.5733)

(.7160)

.03050

.03503

(2.909) (2.973)

$-00002093.00001902$

(.5731) (.6975)

$.0001315 \quad .00009087$

(2.796) (3.988)

.5616

0

(2.159)

0

$-.2858-.3223$

$-.2734 \quad-.3103$

$(7.060) \quad(5.380)$

$.5228 \quad .6893$

(4.082) (4.357)

(4.357) (4.536)

Lawyer

$.2399 \quad .2118$

(3.290) (2.864)

$.34457 \quad .27181$

$.2464 \quad .2339$

(3.351) (3.161)

$.33436 \quad .26441$

.32873

.5779

(2.213)

Public Private

$.5805 \quad 1.520$

$(1.413) \quad(2.817)$

$.1033 \quad .05856$

(5.793) (2.612)

$.02027-.006993$

(.9075) (.1924)

$-.0003758 \quad .0007261$

$(.6327) \quad(.7490)$

$.02835 \quad .03618$

(2.700)

(3.104)

.000008764 .00003964

$(.1521) \quad(.8942)$

$.0001267 \quad .0001374$

$(1.929) \quad(3.818)$

$\mathrm{R}^{2}$

Observations

426

430

426

430

$.17225 \quad .14802$

.16760

.15027

$-.2864$

$-.3213$

$(7.050) \quad(5.347)$

$.5271 \quad .6771$

$(4.095) \quad(4.279)$

.2356

.2249

(3.197) (3.039)

$.17225 \quad .14802$

.19182


that one might obtain a high courman rating for many different reasons, including size of institution, effectiveness of instruction, interest of alumni, quality of students, etc. One might explain the greater effectiveness of Gourman quality in the private schools by the fact that a private school with a high Gourman rating might have obtained that high rating because of different characteristics than those possessed by a public school with high ratings. For example, a private school might be rated high because of the effectiveness of its instructional program, whereas a public school might be rated high because of its size. However, it is useful to note that whether quality is measured in terms of expenditures per student or in terms of this subjective evaluation, the payoff to quality is higher at private institutions. This probably says something about the meaning of the quality variables and implies that a high rating on a quality index of one kind or another might mean a number of things. Probably the privatepublic differentiation is a significant way of subdividing the quality measures. This does not say that private schools are more effective for obtaining higher lifelong earnings than are public institutions. Rather the results imply that if one had to choose between two schools with the same quality ratings, the private school would be the more effective one.

IX. The Interaction Between School Quality and the Ability of the Individuals who Attend

So far we are able to conclude that an individual's lifetime earnings pattern will vary depending upon the nature of the institutions of 
higher education he attends. The traits of universities we observe to be important include subjective evaluations, objective data on institutional differences, college type as defined by the Carnegie commission, and whether or not the institution is under private or public control. Although we have controlled for certain characteristics of the individuals in our sample, the focus so far has been to determine the average impacts of different aspects of institutional quality on incomes of all members of our sample considered together.

It is possible that the impacts of college quality differ depending upon the nature of the individuals attending. That is, college quality differences might be more important, or less important, in a sample of individuals with exceptionally high, or exceptionally low, ability. If the relationship between quality of college attended and subsequent earnings of an individual depends upon the level of the individual's ability then there is said to be an interaction between individual ability and school quality in the earnings relationship. ${ }^{49}$ It is the puxpose of

49 The relationship which includes interaction between ability and college quality may be written

$$
\ln Y=a+b Q+c A+g Q \cdot A,
$$

where ln $Y$ is log of income, $Q$ is college quality and $A$ is the individual's ability. Hence

$$
\frac{d \ln Y}{d A}=b+g A
$$

If $g$ is greater than zero, then the effect of any level of school quality is greater, the higher the ability of the individual concerned. A negative g implies an inverse relationship. This specification assumes a linear interaction between the two continuous dependent variables. Another type of test can be suggested which does not constrain the interaction to be linear. The method involves grouping the sample by similar IQ levels (e.g. IQ quartiles) and estimating earnings functions separately for each IQ quartile. Comparisons can be made of quality coefficients across groups. 
this section to determine whether or not there is an interaction between school quality and individual ability in the sense just described. Pirst, separate regressions similar to those presented in Table 6 (i.e., Including IQ, YRSED, EXF, and EXPSOD along with quality of the last institution attended) were estimated for individuals in our sample with $Y Q^{\prime} s$ above the sample mean (700 observations) and below the mean (811 observations). The question asked is whether the effect of quality differed according to the ability of those who attend. Table 23 presents the elasticities, derived as the product of the coefficient on quality ( $d$ In $Y / d Q$ ) and the mean values of quality. According to the $t$-test, the impact of quality is significantly greater for the higher ability subsample for all definitions of quality but one. 50 (For S.A.T. math the elasticities were not significantly different.) These regressions from which Table 23 is derived reveal that coefficients on IQ were generally maller for the high-ability group; the coefficients on years in school and experience were generally larger for the high-ability group. The model explains 9 to 10 per cent of the vaxiance in 1969 income for those with abllity above the mean, but only 4 to 5 per cent of the variance of income of the lower-ability group was explained. 51

50 The $t$-test was $H_{O}: B_{H}=B_{H}$ is the coefficient of quality for the high ablity half of the sample and $\mathrm{B}_{\mathrm{L}}$ is the quality coefficient for
the low ability half.

51 When S.A.T. and average salaries are put in together, their offects are both more significant ( $t$-test) and larger (size of coefficient) for the high IQ half of the sample. 


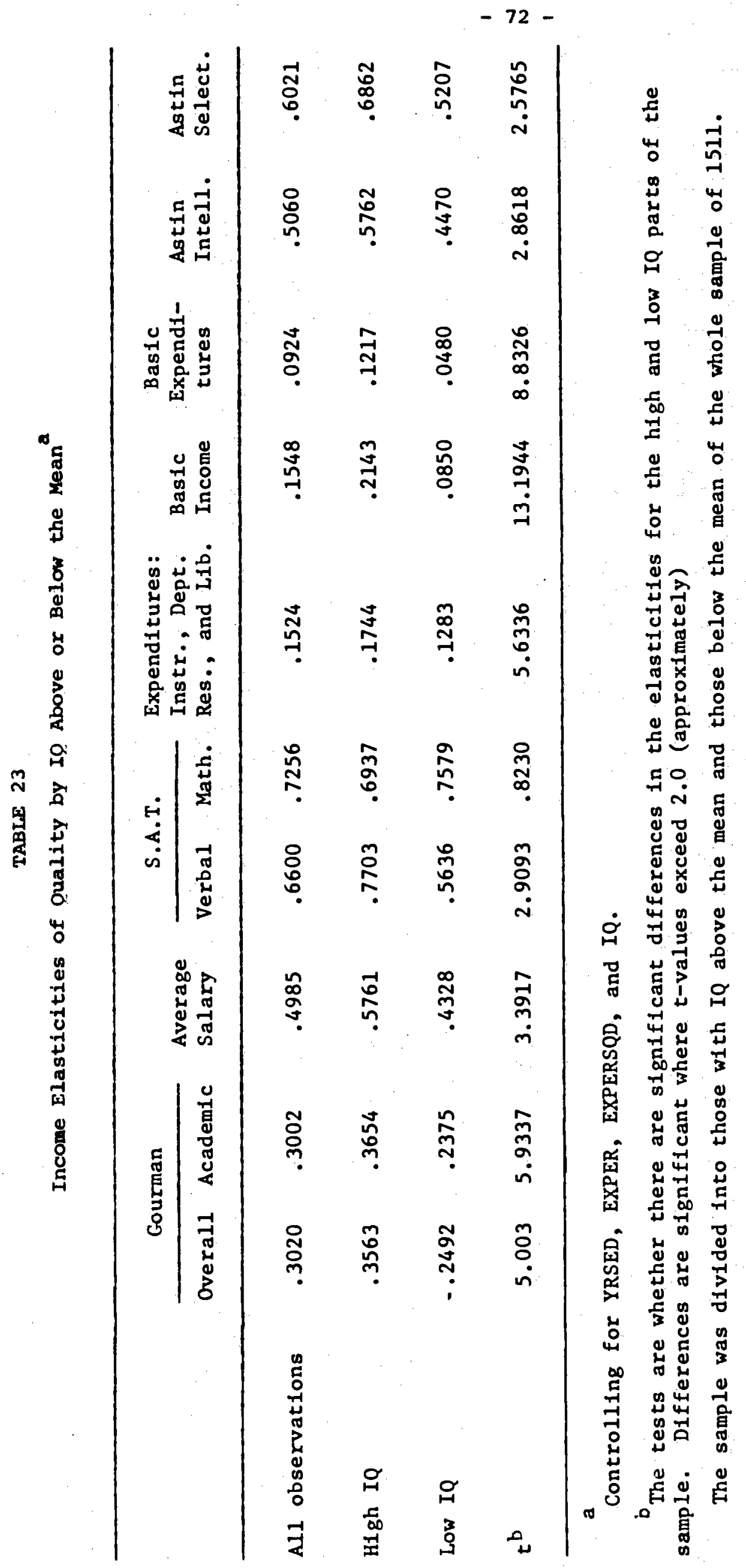


These strong results led us to subdivide the sample further into IQ quartiles, separately for those with sixteen or fewer years of schooling and for those with seventeen or more years of schooling. These regressions appear as Table 24. For the first group the Gourman measure of the quality of the undergraduate institution attended was used, and for those with some graduate training the measure of both undergraduate and graduate institutional quality were inserted. For the undergraduate group the effect of college quality was greatest for the lowest IQ quartile. However from the second lowest to highest IQ quartile college quality appeared to have an increasing effect. For those with some graduate training, this "U-shaped" effect of quality was evident in regard to the measure of graduate institution attended. The lowest IQ quartile had a large and statistically the most significant effect on 1969 earnings. However, from the second lowest to the highest IQ quartile the effects rose, starting with an impact below that of the lowest quartile but rising so that the highest IQ quartile reveals the largest impact of graduate quality on earnings. It should also be noted that undergraduate quality was not statistically significant except in the top IQ quartile for those who had graduate training.

It is interesting that most of the other variables which are used in the earnings functions appearing in Table 24 do not reveal systematic patterns across IQ quartiles for either educational attainment group. Moreover we are never able to explain much more than 10 per cent of the variance in income for those with no graduate training but we always 


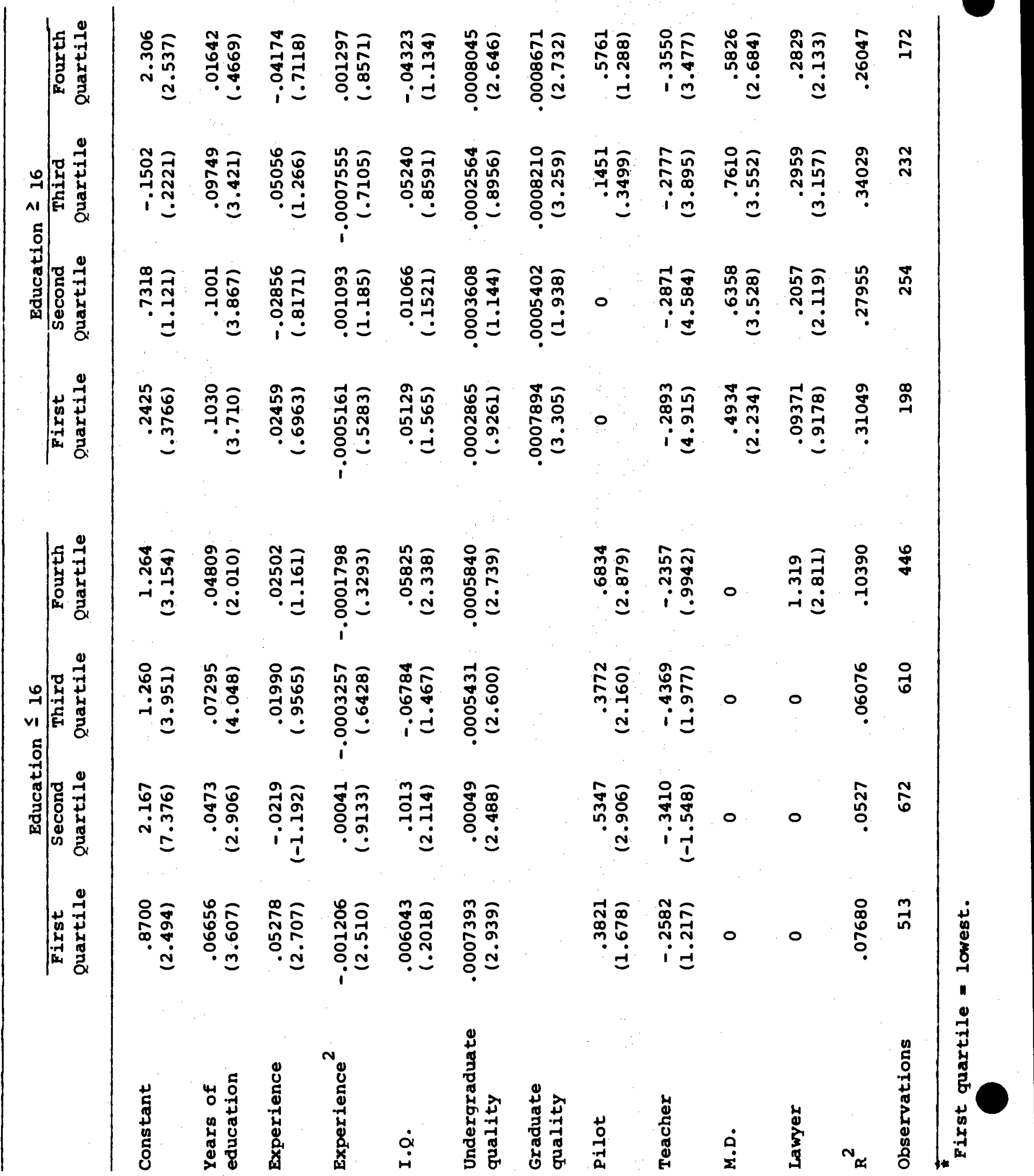


explained over 26 per cent of the variance in income of those with graduate training.

It appears then that regardless of whether or not one went to graduate school the effect of going to a good school was greater for those with greater ability compared to most of those with lesser ability. However, it is also true that those in the lowest ability group were significantly affected by the quality of the institutions they attended, probably as much as those in the highest ability group.

It should be stressed again that no matter what one's ability is, he will be better off attending a good school compared to one of lower quality. However it appears that if one falls into either the top or bottom extreme of the IQ distribution, the impact of going to a good school or to a bad school would be greater than if one falls in the average range of ability. We should also remomber that the sample being studied contains individuals falling in the upper half of the IQ distribution for the nation as a whole. This implies that our top IQ quartile resembles the top eighth in the nation and our botton IQ quartile probably contains people with IQ's slightly above the national norm.

We must also keep in mind the fact that the range of qualities of institutions attended by those in our top quartile probably includes better institutions than are included in the range of institutions attended by those in the lowest IQ quartile. If our estimations had revealed a continuously positive interaction between ability and college quality, this might have been due to the fact that the effect of 
differences in institutional quality were somewhat greater among individuals who attended better quality institutions. However Tables 5 and 6 revealed earlier that the impacts of quality according to relative quality of institutions attended was somewhat tenuous. Hence the "Ushaped" interaction between ability and college quality appears consistent with earlier results.

So far within IQ quartiles we have inserted college quality as a separate variable. The question arises whether the explanatory power of the model would be increased significantly if we insert the measure of quality explicitly as an interactive variable with ability. To this end we have estimated the four equations which appear in Table 25. Equation 1 attempts to explain earnings differences among all those with less seventeen years of schooling by our traditional set of variables including a measure of the quality of the undergraduate institution attended. Equation 3 replaces the single variable measure of undergraduate quality by a set of four variables. First we create four dumy variables. The first being one if an individual falls in the lowest IQ quartile and zero otherwise, the second being one if the individual falls in the second lowest IQ quartile and zero otherwise, etc. For any one individual three of the dummies will be zero and only one will equal one. Each of the four dummies are then multiplied by the quality of the individual's institution. Hence for each individual we have four variables one being the quality of the college the individual attended and the other three being zero. This is a way of seeing 
TABLE 25

Regressions with Quality Interacting with IQ Quartiles in Single Regressions by Attainment

\begin{tabular}{|c|c|c|c|c|}
\hline & Education $<17$ & Education 217 & Education $<17$ & Education 217 \\
\hline & 1 & 2 & 3 & 4 \\
\hline Constant & $\begin{array}{l}1.414 \\
(8.695) \\
\end{array}$ & $\begin{array}{l}.8393 \\
(2.512) \\
\end{array}$ & $\begin{array}{l}1.412 \\
(8.610)\end{array}$ & $\begin{array}{l}.8469 \\
(2.530) \\
\end{array}$ \\
\hline Ed. Yrs. & $\begin{array}{l}.05924 \\
(6.387) \\
\end{array}$ & $\begin{array}{l}.07882 \\
(5.544) \\
\end{array}$ & $\begin{array}{l}.05941 \\
(6.401)\end{array}$ & $\begin{array}{l}.07910 \\
(5.550)\end{array}$ \\
\hline Experience & $\begin{array}{l}.02776 \\
(1.789) \\
\end{array}$ & $\begin{array}{l}.007497 \\
(.3773) \\
\end{array}$ & $\begin{array}{l}.01768 \\
(1.780) \\
\end{array}$ & $\begin{array}{l}.007227 \\
(.3632) \\
\end{array}$ \\
\hline Experience $^{2}$ & $\begin{array}{c}-.0003306 \\
(1.350)\end{array}$ & $\begin{array}{l}.0001151 \\
(.2175)\end{array}$ & $\begin{array}{c}-.0003305 \\
(1.348) \\
\end{array}$ & $\begin{array}{l}.0001274 \\
(.2405)\end{array}$ \\
\hline IQ & $\begin{array}{l}.02425 \\
(4.034) \\
\end{array}$ & $\begin{array}{l}.03488 \\
(4.555) \\
\end{array}$ & $\begin{array}{l}.03366 \\
(2.278) \\
\end{array}$ & $\begin{array}{l}.01940 \\
(1.013) \\
\end{array}$ \\
\hline UGGOVA & $\begin{array}{l}.0005810 \\
(5.515) \\
\end{array}$ & & & \\
\hline GRGOVA & & $\begin{array}{l}.0008332 \\
(6.628) \\
\end{array}$ & & \\
\hline AI x Quality* & & & $\begin{array}{l}.0002331 \\
(2.494)\end{array}$ & $\begin{array}{l}.0002081 \\
(1.838)\end{array}$ \\
\hline $\mathrm{A}_{2} \times$ Quality & & & $\begin{array}{l}.0002047 \\
(4.133)\end{array}$ & $\begin{array}{l}.0002390 \\
(3.731) \\
\end{array}$ \\
\hline $\mathrm{A}_{3} \times$ Quality & & & $\begin{array}{l}.0001900 \\
(3.753)\end{array}$ & $\begin{array}{l}.0003059 \\
(5.250)\end{array}$ \\
\hline $\mathrm{A}_{4} \times$ Quality & & & $\begin{array}{l}.0001201 \\
(1.282)\end{array}$ & $\begin{array}{l}.0003719 \\
(3.168) \\
\end{array}$ \\
\hline Pilot & $\begin{array}{l}.4946 \\
(4.932) \\
\end{array}$ & $\begin{array}{l}.4524 \\
(1.562) \\
\end{array}$ & $\begin{array}{l}.4932 \\
(4.915)\end{array}$ & $\begin{array}{l}.4467 \\
(1.540)\end{array}$ \\
\hline Teacher & $\begin{array}{r}-.3116 \\
(2.817) \\
\end{array}$ & $\begin{array}{c}-.3064 \\
(8.861) \\
\end{array}$ & $\begin{array}{c}-.3094 \\
(2.796) \\
\end{array}$ & $\begin{array}{r}-.3060 \\
(8.838) \\
\end{array}$ \\
\hline $\mathrm{MD}$ & 0 & $\begin{array}{l}.6272 \\
(6.158) \\
\end{array}$ & 0 & $\begin{array}{l}.6278 \\
(6.156) \\
\end{array}$ \\
\hline Lawyer & $\begin{array}{l}1.228 \\
(2.518)\end{array}$ & $\begin{array}{l}.2392 \\
(4.664)\end{array}$ & $\begin{array}{l}1.235 \\
(2.531)\end{array}$ & $\begin{array}{l}.2365 \\
(4.597)\end{array}$ \\
\hline $\mathrm{R}^{2}$ & .027290 & .30468 & .07323 & .30542 \\
\hline Observations & 2240 & 856 & 2240 & 856 \\
\hline $\begin{array}{l}\mathrm{R}^{2} \text { Prior to } \\
\text { Occupations }\end{array}$ & .05679 & .16503 & .05720 & .16673 \\
\hline
\end{tabular}

*The quality measures used in Colum 3 are for the undergraduate institutions and the quality measures used in Colum 4 are for the graduate institutions attended by the individuals. 
whether quality has a differential impact depending upon which ability quartile the individual falls in. similarly equation 2 estimates the generalized earnings function for those with some graduate work, and column 4 is the same equation but with quality measures for the graduate institutions attended being sorted into four IQ groups.

In equations 3 and 4 we are basically asking the same type of question as were asked when the sample was subdivided and equations estimated separately for individuals falling into different IQ quartiles. However in the equations currently being considered we constrain coefficients on years of schooling, experience, IQ, and the occupational effects to be the same for all individuals within a schooling attainment category. Hence in one respect these latest estimates are less general and more restrictive than the ones in the previous tables. It is interesting to note that for undergraduates in this case the coefficients on quality fall continuously from the lowest to the highest IQ quartile. Indeed the coefficient on the quality variable multiplied by the highest IQ dumny is not even statistically significant. On the other hand the quality coefficients for those with some graduate work rise continually from the lowest to the highest IQ quartile. Since there is no reason to constrain the model such that other variables have the same effect regardless of the individual's IQ category, more reliability should be placed on the equations in Table 24. 
The latest table was prepared to see if the total power of the model has increased when interaction is explicitly introduced. The $R^{2}$ in equation 1 when quality was introduced as a single variable for undergraduates was .0729 and the $R^{2}$ in equation 3 when quality was interacting with four IQ dumies was .0732 . An F-test to determine whether or not there was a significant difference in $R^{2}$ 's between the two equations revealed very clearly that there was no significant difference. Similarly when comparing equation 2 and equation 4 there was no significant difference in $R^{2} \cdot 8$ of .3047 and $.3054 .^{52}$

We can conclude that institutional quality is a significant factor in determining an individual's lifetime earnings. Moreover most tests reveal that the impact of quality is somewhat greater for individuals with more ability compared to individuals with less. However it does appear that the least able in our sample (who resemble the average individual in the society as a whole) are affected by the quality of the institution they attended by roughly the same amount as are the top people in terms of ability in our sample. Moreover, it seems that any tests of interaction between institutional quality and individual ability should be based on estimates of earnings functions which allow other variables therein to take different values for individuals of different levels of ability. That 18, inconsistencies in results develop when the

${ }^{52}$ In both cases the significant F-level at 5 per cent was 2.60 and the $F$ for undergraduates was .32 and for graduates .57 . 
model is constrained such that all individuals in the sample are similarly influenced by years attended, experience, occupational choice, and the like. However, the differences in impacts of institutional quality on individuals of different levels of ability do not appear to be major. our model's explanatory power is not strengthened when we introduce college quality as a variable explicitly interacting with ability. If there is an interaction, the foint influence of quality and ability does not add much to the separate influences of the two factors on income.

It probably is sufficient to assert that both institutional quality and individual ability are significant factors in the earnings function and stop there. A policy implication is that each individual should seek the best quality schools possible regardless of ability. If the question for the broader society is whom to encourage to attend the institutions of highest quality the problems become confounded and very difficult. It appears that the most able students should be encouraged to attend the best schools because their income from so doing will increase by the largest percentage as revealed by the coefficients on quality. However, the policy question involves much more than efficiency since even the least able students will get extra income from going to a better school. One further attempt to get at the relationship between individual ability and institutional quality was made. Separately for those with sixteen or fower and seventeen or more years of schooling, the sample was divided into those with $I^{\prime}$ 's above the mean and those with IQ's below the mean. Within each of these IQ halves the sample was divided 
into those who attended schools of above mean quality and those who attended schools of below mean quality. For each attainment level four samples of individuals were obtained: those with below average ability at below average institutions, those with below average ability at above average quality institutions, those with above average ability at above average institutions, and those with above average ability at below average institutions. These results are presented in Table 26. Once again when comparing the eight separate earnings functions estimated, the results are more or less systematic but the reasons for them are somewhat unclear. Within only one of the eight estimates were differences in individual abilities significant in explaining 1969 income. Ability differences among individuals with some graduate training, below average $I Q$, attending below average quality institutions had a significant effect. But this was the only case. On the other hand in seven of the eight estimates differences in years attended had a significantly positive effect on later income. For undergraduates the coefficient on years was most important in the high IQ, high college quality group. We must remember that the years coefficient in this case is constrained to being no greater than sixteen and so this result might be interpreted that among all those with a B.A. or less who attended college, the payoff to attending would be greatest if you graduated and if you graduated from a better-thanaverage quality school and had above average IQ. It should be pointed out that the coefficient on years in this case was lower than that coefficient in virtually all of the cases of people attending for more than sixteen years. For some reason, those doing graduate work with lower than average 
ability attending high quality institutions did not have a significant payoff to additional years of schooling beyond bachelor's degrees. However those with lower than average ability doing graduate work at lower than average quality institutions found the largest rewards to attending for extra years: in this case, getting the graduate degree probably had special value in detracting from the Individual's abllity and institutional quality.

The coefficients on the relevant quality measures appear more systematic and quite interesting. For both attainment categories individuals attending the high quality institutions were revealed to have a significantly positive relationship between quality of institution and subsequent earnings. This result applied to individuals in both the high and low IQ halves of the sample. On the other hand, individuals who attended institutions of below average quality revealed that differences in quality of institutions attended did not significantly affect income regardless of attainment and of whether or not they were above or below average in IQ. For undergraduates it appeared that the returns to quality of their institution attended were greater and more significant for those with below average $\mathrm{I} Q$, implying something of a trade-off between institutional quality and individual'a ability. For those with some graduate work, the coefficlent on quality was larger for those in the higher IQ higher quality subset although the difference between this coefficient and the coefficient on quality for those (with below average ability) in high quality institutions was very small. Finally, it should be noted that the coefficient on years attended and on quality were lowest 
for those without graduate training who fell in both the below average ability and below average college quality categories. The explained variance was the lowest in this case as well. As usual, we can explain substantially more of the variance for those with more than sixteen years of schooling.

Once again when we subdivide the sample into such fine detail, we get results which differ depending upon the category studied. However it does appear that there are positive interactions in a number of the cases. Differences in individual abilities, years of schooling obtained, and quality of institutions attended have generally significant effects on lifetime earnings patterns. The magnitude of the relationship between any of these explanatory variables and income varies but in no case is the explanatory variable able to explain huge amounts of the variance of income. Indeed the $\mathrm{R}^{2}$ never goes above .35 , even when the independent variable list includes dummies for certain professions and occupations. It is sufficient to say that each of the three major variables are significant in contributing to the earnings model, and this is based primarily on the consistency of the positive impacts of institutional quality, ability, and years of schooling on subsequent earnings rather than on the revelations regarding interaction among these. 
X. The Introduction of Family Background Variables

The "proper" method of measuring socio-economic status is still being debated. Karabel and Astin ${ }^{53}$ have recently argued that socio-economic status is positively correlated with college quality. If this is so, then omission of SES as an explanatory variable has biased upward the effects we attribute to quality. Moreover, Hauser ${ }^{54}$ and Bowles ${ }^{55}$ have attempted to prove that father's income (rather than education or occupational status) is the appropriate measure of SES.

Our data set has measures of father's educational attainment and father's occupational status. The latter is composed of three dummies (indicating high, medium, and low). We also have a measure of wife's father's education. Each of these has been used to stand for SES and are probably correlated with father's income which we do not have.

Table 27 introduces the SES variables available in our sample into our standard earnings functions separated by those with and without graduate training. Several facts stand out. The introduction of SES measures reduces the size and statistical significance of the quality variables

${ }^{53}$ Karabel, J., and Astin, A.W. "Social Class, Academic Ability, and College 'Quality'." Unpublished manuscript, Office of Research, American Council on Education, June 1972.

54 Hauser, R.M., Lutterman, K.G., and Sewell, W.H. "Socio-Economic Background and the Earnings of High School Graduates." Paper presented at the meeting of the American Sociological Association, Denver, August 1971.

${ }^{55}$ Bowles, op. cit. 
TABLE 27

Earnings Functions Including Socioeconomic Background Variables

\begin{tabular}{|c|c|c|}
\hline Constant & $\begin{array}{r}1.327 \\
(8.049)\end{array}$ & $\begin{array}{r}.6285 \\
(1.835)\end{array}$ \\
\hline $\begin{array}{l}\text { Years of } \\
\text { education }\end{array}$ & $\begin{array}{r}.05343 \\
(5.776)\end{array}$ & $\begin{array}{r}.08074 \\
(5.653)\end{array}$ \\
\hline Experience & $\begin{array}{r}.01607 \\
(1.632)\end{array}$ & $\begin{array}{l}.002790 \\
(.1405)\end{array}$ \\
\hline Experience $^{2}$ & $\begin{array}{r}-.0002880 \\
(1.185)\end{array}$ & $\begin{array}{r}.0002585 \\
(.4889)\end{array}$ \\
\hline$I \cdot Q$. & $\begin{array}{l}.02260 \\
(3.774)\end{array}$ & $\begin{array}{r}.02935 \\
(3.752)\end{array}$ \\
\hline $\begin{array}{l}\text { Undergraduate } \\
\text { quality }\end{array}$ & $\begin{array}{r}.0005142 \\
(4.802)\end{array}$ & $\begin{array}{r}.0004266 \\
(2.866)\end{array}$ \\
\hline $\begin{array}{l}\text { Graduate } \\
\text { quality }\end{array}$ & & $\begin{array}{r}.0006879 \\
(5.192)\end{array}$ \\
\hline Father's SES high & $\begin{array}{r}.08156 \\
(2.531)\end{array}$ & $\begin{array}{r}.01462 \\
(.3394)\end{array}$ \\
\hline Father's SES Med. & $\begin{array}{r}.03953 \\
(1.209)\end{array}$ & $\begin{array}{l}.04322 \\
(.9994)\end{array}$ \\
\hline Father's education & $\begin{array}{l}.002872 \\
(.9008)\end{array}$ & $\begin{array}{r}-.001611 \\
(.4187)\end{array}$ \\
\hline $\begin{array}{l}\text { Wife's father's } \\
\text { education }\end{array}$ & $\begin{array}{r}.01350 \\
(4.200)\end{array}$ & $\begin{array}{l}.007247 \\
(1.862)\end{array}$ \\
\hline Pilot & $\begin{array}{r}.4987 \\
(5.010)\end{array}$ & $\begin{array}{r}.3948 \\
(1.365)\end{array}$ \\
\hline Teacher & $\begin{array}{l}-.2851 \\
(2.596)\end{array}$ & $\begin{array}{l}-.2925 \\
(8.418)\end{array}$ \\
\hline M.D. & $\begin{array}{l}0 \\
0\end{array}$ & $\begin{array}{r}.6245 \\
(6.151)\end{array}$ \\
\hline Lawyer & $\begin{array}{r}1.136 \\
(2.346)\end{array}$ & $\begin{array}{r}.2226 \\
(4.332)\end{array}$ \\
\hline $\mathrm{R}^{2}$ & .08906 & .31581 \\
\hline Observations & 2241 & 856 \\
\hline $\mathrm{R}^{2}$ prior to occupations & .07373 & .19162 \\
\hline
\end{tabular}


only very slightly and these quality variables are still powerful in explaining individual income differences. 56 It is also interesting that for those without graduate work, incomes were significantly positively affected by the educational attainment of wife's father and if one's own father was in an occupation in the top third of the status scale. However none of the SES measures were significant in explaining income differences among those with graduate training. Despite the power of the SEs variables in the lower educational attainment group, we can explain only 9 per cent of the variance in log of income there but 31 per cent of the variance for those with more than sixteen years of school. These results do not change when the occupational dumies are dropped except that wife's father's education becomes significant for the graduate group as well. In this case the differences in proportion of variance of income explained is smaller. When regressions were run by IQ quartiles including the SES measures, the same U-shaped patterns appeared for the quality variables.

Unless our SES measures are grossly inadequate, which is doubtful, it appears that college quality has impacts above those which might really be reflecting family background. Once again it appears that quality of schools attended has a real effect and is not merely a proxy for other factors.

\footnotetext{
${ }^{56}$ For comparison see the 1969 regressions in Table 12.
} 
XI. Implications

We have found that quality of institutions of higher education has an important impact on lifetime earnings of those who attend. A subjective evaluation of institutions (the Gourman index) was used to measure quality in many of the estimated equations, but it appears that certain objective traits which contribute to these evaluations can be isolated. In particular, average student quality as measured by the average SAT scores of entering freshmen, and faculty salaries are strongly related to the Gourman index. and the most important of the measureable institutional traits in the earnings functions of former students.

Quality seems to be more important for students with more years of higher education and also for more able students. It affects later incomes more than it influences incomes immediately upon entering the labor force. Differences in institutional quality among private colleges are more important than those among public schools. These results hold even after controlling for certain occupational choices, individual ability, and socio-economic background.

There are certain limitations on the usefulness of the results as presented so far. Although we have made statements about the statistical relationship between school quality and later earnings, we have been unable to do much cost-benefit or rate of return analyses. That is, although the average SAT scores of entering freshmen is a significant factor in later earnings of individuals who attend, we do not know (1) how a school might go about improving the average SAT's, 
(2) how much it would cost to raise average SAT's by any amount or percentage, and hence, (3) the rate of return to students (and presumably the school) of the school successfully raising the average SAT scores of its students. Almost all our measures of quality cannot easily be considered in cost terms, and so rates of return to these aspects of quality are impossible to estimate.

However, we do have data on average expenditures per student for faculty, research and library which we have used to measure college quality at times throughout this study. It is possible to get something like an estimate of the rate of return to these expenditures, by considering the percentage change in 1969 income of a student for a given percentage change in per student expenditures roughly 20 years earlier. For the following calculations we use the 1969 earnings functions in Table 13 where quality is measured by per student expenditures.

By multiplying the mean expenditures per student times the coefficient on the expenditure variable we can get the percentage change in an individual's 1969 income for a percentage change in expenditure per student at the institution he attended earlier. 57

${ }^{57}$ The coefficient on expenditures is $\frac{\text { dln Inc }}{d \text { Exp. }}$ and $\frac{d \ln I n c}{d E x p} \quad$ time mean expenditures

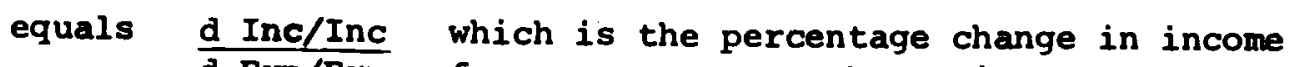
d Exp/Exp for a one percent change in expenditures. 
For those with 16 or fewer years, a one percent change in per studente expenditures at their undergraduate college resulted in a .147 percent increase in 1969 income; and for those with graduate attendance, a one percent increase in per student expenditures by the graduate schools resulted in a .180 percent increase in 1969 income.

Using sample means for 1969 incomes of our sample members and per student expenditures by the institutions, it can be shown that a one dollar per student increase in spending by an institution would result in an increase in income twenty years later of $\$ 2.51$ for those with 16 or fewer years and of $\$ 2.82$ for those with 17 or more years. 58 When evaluating this investment by the schools for the government or alumni who finance institutions) in increasing per student spending, we must recognize that the payoff we have reported comes twenty years after the fact. Hence we must ask what is the value today of $\$ 2.51$ tweny-one years later in one case, and of $\$ 2.82$ nineteen years later in the other. This, of course, requires knowledge about discount rates applied by those to whom the benefits will accrue.

\section{The relevant means are as follows:}

1969 income
Per Student Expenditures
Job Experience in 1969

For example a 1 increase in spending per undergraduate (i.e. \$9.66) would result in a $\$ 24.26$ increase in 1969 income $(.00147$ times $\$ 16,500)$. Hence, a $\$ 1$ increase in spending would imply a 1969 salary increment of $\$ 2.51$. These results are holding constant other variables in the earnings functions. 